Pacific Northwest

National Laboratory

Operated by Battelle for the

U.S. Department of Energy

\title{
Evaluation of UT Wall Thickness Measurements and Measurement Methodology
}

DR Weire

AF Pardini

August 2007

Prepared for the U.S. Department of Energy under Contract DE-AC05-76RL01830 


\section{DISCLAIMER}

This report was prepared as an account of work sponsored by an agency of the United States Government. Neither the United States Government nor any agency thereof, nor Battelle Memorial Institute, nor any of their employees, makes any warranty, express or implied, or assumes any legal liability or responsibility for the accuracy, completeness, or usefulness of any information, apparatus, product, or process disclosed, or represents that its use would not infringe privately owned rights. Reference herein to any specific commercial product, process, or service by trade name, trademark, manufacturer, or otherwise does not necessarily constitute or imply its endorsement, recommendation, or favoring by the United States Government or any agency thereof, or Battelle Memorial Institute. The views and opinions of authors expressed herein do not necessarily state or reflect those of the United States Government or any agency thereof.

\section{PACIFIC NORTHWEST NATIONAL LABORATORY}

operated by

BATTELLE

for the
UNITED STATES DEPARTMENT OF ENERGY
under Contract DE-AC05-76RL01830
Printed in the United States of America
Available to DOE and DOE contractors from the
Office of Scientific and Technical Information,
P.O. Box 62, Oak Ridge, TN 37831-0062;
ph: (865) 576-8401
fax: (865) $576-5728$
email: reports@adonis.osti.gov

Available to the public from the National Technical Information Service,

U.S. Department of Commerce, 5285 Port Royal Rd., Springfield, VA 22161

ph: (800) 553-6847

fax: (703) 605-6900

email: orders@ntis.fedworld.gov

online ordering: http://www.ntis.gov/ordering.htm

This document was printed on recycled paper. 
PNNL-16828 Rev. 0

\section{Evaluation of UT Wall Thickness Measurements and Measurement Methodology}

DR Weier

AF Pardini

August 2007

Prepared for

the U.S. Department of Energy

under Contract DE-AC05-76RL01830

Pacific Northwest National Laboratory

Richland, Washington 99352 


\section{Summary and Recommendations}

AREVA NC Inc. (AREVA), under a contract from CH2M HILL Hanford Group (CH2M HILL), performs ultrasonic (UT) examinations of selected portions of double-shell tanks (DSTs). The purpose of these examinations is to provide information that could be used to evaluate the integrity of the walls of the primary tank and secondary liner. The requirements for the ultrasonic examinations are to detect, characterize (identify, size, and locate), and record measurements made of any reportable wall thinning, pitting, or cracks that might be present in the wall of the primary tank. Under the contract with CH2M HILL, all data is to be provided to PNNL for third-party evaluation.

CH2M HILL has requested that PNNL examine the ultrasonic methodology utilized in the inspection of the DSTs. Specifically, PNNL is to evaluate the various factors in the UT process variability and capability to detect changes in wall thickness and to document the UT operator's techniques and methodology in the determination of the reported minimum and average UT data and how it compares to the raw (unanalyzed) UT data.

Throughout this document the term "analyst evaluation" is used to denote the methodology performed by the UT inspector during his analysis of the data. The inspector utilizes the imaging software provided by Force Technologies Inc., which is the vendor of the UT equipment used in the inspection of the DSTs. The inspector relies on visual judgments of the imaged UT data to ascertain his minimum, average, and maximum wall thickness estimates.

Evaluation of the wall thickness measurement results for six tanks inspected in 2007 and previously inspected between 1998 and 2001 leads to the following conclusions and recommendations.

\section{Measurement Precision and Accuracy Topics}

The following three precision and accuracy topics (i.e., Inspector UT determination versus computer data analysis, Variability of UT results from Qualification Testing, and Adjacent Path assessment) were evaluated resulting in the conclusions listed. Additional topics, such as UT differences on rusted versus cleaned surfaces, repeated DST UT scans, and affect on repeatability from UT equipment and calibration block temperatures versus tank temperature, etc.; will be added in revision 1 to this report.

\section{Analyst Evaluation of UT Data versus EXCEL Spreadsheet Evaluation}

Based on direct comparison of the analyst evaluation results of UT images and the computer evaluation of EXCEL spread sheets, many reasons are noted for keeping the analyst evaluation approach. Generally comparable results are obtained through the EXCEL computations, but when substantial differences do occur, it's because the EXCEL approach cannot readily address special anomalous situations (e.g., lift-off and touch down errors, material laminations, noisy data, etc.) that can be recognized by a trained analyst. Continuation of the analyst evaluations is recommended. 
However, within such analyst evaluations, standardizing the estimation approach for maximum values per UT image is recommended. In turn, an appropriate method for using such maximum values over a plate/riser combination, to obtain an actual plate thickness, should be established. This actual plate thickness value is needed to compute wall thickness losses, which are used in extreme value statistical estimation where measured losses can be statistically combined across several plates or plate courses. Under current inspection and analysis methodology, variability between plates is indeed one of the most prominent sources of variability in estimating wall thickness loss; this is most likely due to not knowing the actual starting thickness (versus nominal thickness) of the various plates. The large variability likely stems from the estimation of original thickness from drawing specifications, rather than in the measurement of the current remaining wall thickness.

\section{Operator Qualification Data Examination}

Minimum thicknesses are reported by the UT operator in UT qualification testing for pitting and thinning test plates. When this data for both thinning and pitting is statistically combined (includes test Plates 1 and 3 (pit plates), and 5 (thinning plate)), and when one considers both the repeatability between measurements of a specific test plate area, and the differences from the "true" thickness of that area; then $\mathrm{a} \pm$ two standard deviation uncertainty range for a single measurement is \pm 25.0 mils. For repeatability only, without regard for the accuracy in matching the true values (again for pitting and thinning plates combined), the + two standard deviation range is \pm 23.4 mils. It can thereby be observed that differences from the true value add little to the uncertainty of measurements, and most uncertainty is due to the lack of repeatability

If we consider the thinning Plate 5 alone, the \pm two standard deviation range is reduced to \pm 16.6 mils. This is probably the best measurement uncertainty range that might be applied to the typical minimum UT image wall thickness for tank inspections if indeed the testing capability of tanks in the field is comparable to the qualification results (i.e., we have not yet explored the effect of surface condition).

Note however that the uncertainty of a single measurement will not typically be the driver in decision making. Rather the mean over many such measurements will be of importance, and the uncertainty associated with the mean of multiple measurements will decrease from the individual measurement uncertainty as the number of measurements increases. In addition, the difference between two independent measurements would often be of interest, and then the variance of the difference in the measurement (assumed with independent error) would be doubled with the standard deviation of the difference increased by a factor of the square root of two as in $\pm 1.414 \times 2 \times 8.3= \pm 23.5$ mils. So for any two measurements of minimum wall thickness to be considered different from each other, their difference would have to fall outside that range. 


\section{Adjacent Path Comparisons}

At the time of this revision 0 report, there are no directly repeated measurements in the tank inspections with which to examine measurement repeatability. The closest we can come is by comparing adjacent UT images from adjacent paths under the assumption that the tank area is actually quite similar in these two areas. This was done by comparing Path 1 and Path 2 adjacent images over all the 2007 tank inspections. The resulting \pm two-sigma difference range was \pm 21.2 mils. This is somewhat surprisingly small. It actually shows better repeatability between the minimum thickness in adjacent tank areas to be less than the repeatability indicated by the qualification data ( +23.5 mils) for the difference in two measurements. But these results are certainly comparable with the conclusion being that the measurement methodology carries from the qualification test plates to the field tanks in a very adequate manner.

As already stated, there may be little value in characterizing the repeatability, or measurement error, associated with a single measurement, or in the difference between two measurements. Rather the mean over many such measurements, or more specifically, the mean over many differences in measurements, should be evaluated relative to the standard deviation shown over the many such measurements to determine their statistical significance.

\section{Old Inspection versus New Inspection Comparison}

Unfortunately, changes in re-inspection practices when adjacent paths are found to show an offset in results bring into question the value of comparisons of the old and new inspections to examine the changes in tank wall thicknesses. The measurement approach has fundamentally been changed from the original baseline UT data, due to the new re-inspection decisions that attempt to eliminate significant/unexpected offsets between the paths, by immediate re-inspection. This was not done in the older inspections, and path differences are apparent in those measurements.

It is feared that the results of old minus new comparisons are driven more by such systematic differences between paths in the older inspections. Current re-inspection is thought to give more accurate wall thickness results. Since the systematic path differences were left alone in the older data, it can certainly be the case that both paths could indeed somewhat systematically differ from the truth, and then comparison to current more accurate results don’t truly show actual changes in wall thickness.

Old to new comparisons were done in any case in this report, with the caveat that differences might be due to changed measurement methodology rather than actual wall thickness change. In so doing, some tanks show wall thickness loss, some show no change, and some show wall thickness gain. Presently, the UT methodology for wall thickness "loss" is not considered reliable since either 1) new measurements have to be compared to questionable original nominal wall thickness or 2) new measurements have to be compared to old measurements that might differ since path re-inspection conventions have changed. Instead separate corrosion loss determinations are being done by established electrochemical determination from actual waste (Duncan 2007). The UT measurement process should be kept as consistent as possible between old and new inspections to avoid this type of situation. And it is also 
noted that for corrosion studies, it is very desirable to continue to return to the same riser/path/UT image locations as was done for the old and new inspections examined in this report.

\section{Riser Differences}

Two risers were inspected per tank in 2007 based on a 2001 study of Tank 241-AY-101, the only tank at the time that used multiple risers (four actually) in an inspection. Riser variability was indicated, so rather than incorporating an extra uncertainty buffer when inspecting only a single riser, it was decided to inspect two risers instead. Now however it is shown in this report that such riser differences are not indicated in the more extensive set of tanks that now have inspections completed using multiple risers.

Since riser variability does not appear to contribute to variability in wall thickness loss in the 2007 inspections, there appears to be little reason to continue the multiple riser requirement in tank inspections. More paths down a single riser would likely offer better information (i.e., 4 scans from one riser, versus 2 scans from two different risers). And if the systematic differences between paths that influenced the older inspections, as discussed above, continue to occur, the needed re-inspections will be more readily identified when 3 or 4 paths have been inspected down the single riser.

For extreme value statistical estimation a single riser should be sufficient, but adequate numbers of measurements are still needed, which is another reason for 3 or 4 paths down from a single riser. 


\section{Contents}

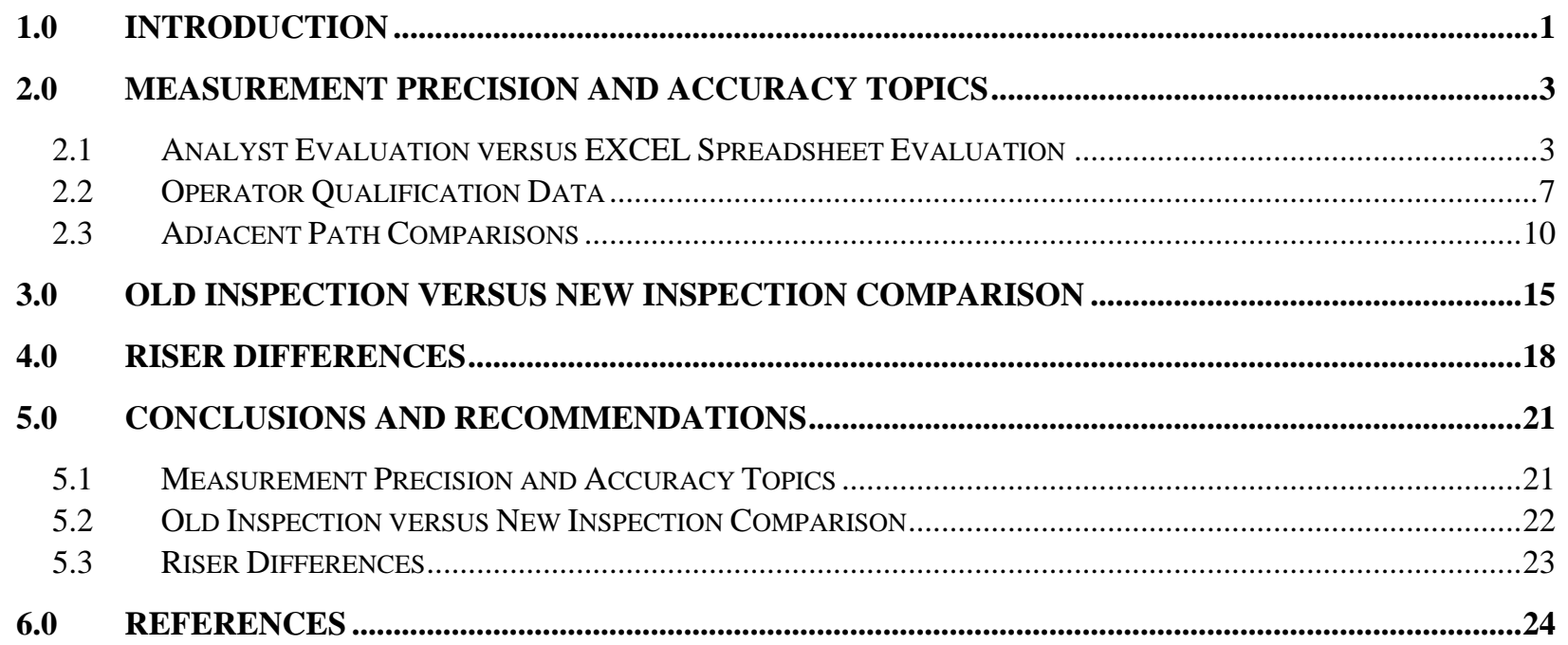

Appendix A

Distribution 


\section{Figures}

2.1 Analyst Evaluation Minus EXCEL Differences ....................................................... 5

2.2 Analyst Evaluation Minus EXCEL Difference Summary Results ..................................... 6

2.3 Measured Minus True Values from Qualification Data ................................................ 7

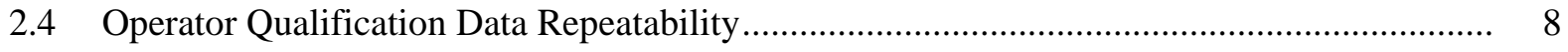

2.5 Operator Qualification Data Repeatability by Test Plate .................................................. 10

2.6 Path 1 Minus Path 2 for Adjacent UT Images ................................................................ 12

2.7 Path 1 Minus Path 2 Difference Summary Values........................................................... 12

2.8 Path 1 Minus Path 2 Including Old Inspections............................................................. 14

3.1 Old Minus New Differences for UT Images.................................................................... 16

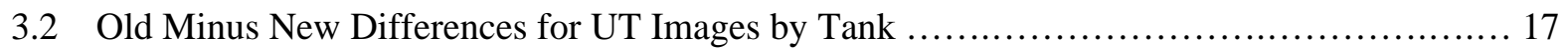

4.1 Variance Component Analysis for Examination of Riser Differences .................... 19

4.2 Variance Component Analysis with and without Tanks AY-101 and AY-102.............. 20 


\subsection{Introduction}

AREVA NC Inc. (AREVA), under a contract from CH2M HILL Hanford Group (CH2M HILL), performs ultrasonic (UT) examinations of selected portions of double-shell tanks (DSTs). The purpose of these examinations is to provide information that could be used to evaluate the integrity of the walls of the primary and secondary tank. The requirements for the ultrasonic examinations are to detect, characterize (identify, size, and locate), and record measurements made of any wall thinning, pitting, or cracks that might be present in the wall of the primary tank. Under the contract with CH2M HILL, all data is to be provided to PNNL for third-party evaluation. Any measurements that exceed the requirements set forth in CH2M HILL reporting criteria such as Engineering Task Plan (ETP), RPP-Plan-27202 (Jensen 2005), are to be reported to CH2M HILL and the Pacific Northwest National Laboratory (PNNL) for further evaluation. Specific measurements that are reported include the following:

- Wall thinning that exceeds $10 \%$ of the nominal thickness of the plate.

- Pits with depths that exceed $25 \%$ of the nominal plate thickness.

The accuracy requirements for ultrasonic measurements for the different types of defects are as follows:

- Wall thinning - measure thickness within \pm 0.020 in.

- Pits - size depths within \pm 0.050 in.

Under contract from CH2M Hill, qualification of personnel participating in the DST inspection program, the UT equipment (instrument and mechanical scanning fixture), and the UT procedure that will be used in the examination of the current DST is required. Personnel participating in the UT examinations are to be certified in accordance with American Society for Nondestructive Testing (ASNT) Recommended Practice SNT-TC-1A, 1992 Edition, and associated documentation attesting to their qualifications is provided. The capability of the UT system is validated through performance demonstration test (PDT) on a mock-up (test plates) simulating the actual DST. The current procedure for the UT is based on requirements listed in the American Society for Mechanical Engineers (ASME), Boiler and Pressure Vessel Code Section V, Article 4, Ultrasonic Examination Methods for Inservice Inspection.

The ability of the ultrasonic inspection equipment and operators to detect and accurately size indications and wall thinning to the above criteria has been used in this report. The PDT utilizes a set of test plates that have been characterized using mechanical and ultrasonic methods to ascertain the "true" state of the plate conditions. UT operators are required to use the same equipment that is currently being used for the inspection of the DSTs and perform a blind inspection of the plates. Each inspector is evaluated against the established "true" state condition and must be within the limits established in the above criteria. The PDT plate data used in this report is focused on ascertaining how well the UT operator can perform wall thinning evaluations (i.e. evaluate specifically remaining wall condition resulting from thinning or pitting). 
This report did not focus on cracking data that is also available from the PDT. The reason is twofold. PNNL establishes the "true" state of cracks in the test plates by using similar ultrasonic techniques as that used by AREVA. The test plates have not been destructively analyzed to verify the actual crack depths; hence the comparison is not rigorous. The other reason for not focusing on cracks as part of this analysis is no data exists from a verified crack found in the field on a Hanford DST. A linear indication (not verified as a crack) however does exist in DST 241-AP-108 which will be examined again in FY 2008. The data from this linear condition can then be compared to the data acquired in the initial scans done in FY2000 and FY2002. The evaluation in FY2002 indicated no growth in the indication in length, depth, or signal amplitude which could indicate a fabrication anomaly. A cracking analysis similar to the thinning analysis performed in this report could be initiated after the next AP-108 inspection.

The premise of this report is to establish a foundation for a corrosion analysis. This report investigates various data sources including the PDT and tank wall thinning studies to determine characteristics of the ultrasonic measurement process and its ability to perform to these expectations. 


\subsection{Measurement Precision and Accuracy Topics}

This report provides the results of investigations of data sources with respect to UT scanning measurement precision and accuracy. Precision, or repeatability, can be addressed using both field data from tanks and operator qualification data from test plates. Accuracy can generally only be addressed through the operator qualification data where true thickness values are known.

The first topic is a comparison of the current analyst evaluation method of tank scans as compared to what might be obtained if the process were automated through the use of EXCEL spreadsheets. Then the operator qualification data are examined later in this section, and finally comparisons of results from sideby-side images in adjacent paths from tank inspections are discussed.

\subsection{Analyst Evaluation versus EXCEL Spreadsheet Evaluation}

The raw UT image data, at pixel resolution, were obtained for three separate tank measurement paths. They include a single path from Riser 29 in Tank 241-AW-103, and adjacent paths 1 and 2 from Riser 89 in Tank 241-AY-102. The paths were typically split into about 34 UT images, each of which is 12-in. (vertical) by 15-in. (horizontal). Analyst evaluations of such UT images currently used for tank measurements generate a minimum, average, and maximum value for each 12 -in. by 15 -in. UT image. Note that the average value from this analyst evaluation is actually the wall thickness that is roughly exceeded, and not exceeded, for one-half the image area; therefore this value more closely approximates the median of the image pixel measurements rather than their average. An analysis of how the UT operator chooses the value for minimum, average, and maximum is provided in Appendix A.

The same UT images for the paths mentioned above were used to generate large EXCEL spreadsheets; in fact due to EXCEL restrictions, only one-half of each image could be evaluated at a time to generate a minimum, average, median, and maximum values. The overall image values were then computed by appropriately combining the two halves' summary results. This is appropriate for the minimum, average, and maximum values over the entire image, but the midpoint of the two medians was used for the entire image, and this is not necessarily the precise median of the combined halves of the UT image, but it should provide a reasonable approximation.

It was readily apparent that a comparison of the EXCEL and analyst evaluation maximum values would not be of particular value since the EXCEL values essentially always generated larger values than the analyst evaluation with many being considerably larger. Clearly "expert knowledge" was applied in the analyst evaluation approach to eliminate relatively large EXCEL values that are in fact due to measurement noise; it would be difficult to use spreadsheet analyses to mimic this feature of the analyst evaluation, and as a result maximum values are not included here.

Note however, that evaluation of maximum values is indeed a very important topic in estimating extreme value wall thickness losses in tanks. The individual tank inspection reports issued in the past year have used such losses to facilitate combining measurements over plates of unequal nominal 
thicknesses. If drawing nominal values are used as the initial tank wall thickness, negative losses (that is, gains) in wall thickness usually result since plates are still thicker than drawing nominal. For this reason the maximum values from all the UT images in a plate/riser combination are used to estimate wall thickness for a rather pristine area of the plate. Now such areas will obviously vary considerably between tanks in just how pristine the plate area is in the vicinity the maximum values. In some tanks with more corrosion, it is quite close to drawing nominal, while for others, it could be as much as 40 mils greater than nominal.

The nominal plate thickness approach used in the reports doesn't use the single largest of the maximum UT image values in a plate/riser combination, but rather approximately a $90^{\text {th }}$ percentile so as to avoid overestimating the original plate thickness. It was subsequently found that in the analyst evaluation approach, the reported maximum values are also "backed off" somewhat from the observed maximum values in the image. Standardizing this estimation approach of maximums and resulting original wall thicknesses is desirable so that wall thickness loss can be better characterized.

Because of the inherent differences in the maximum values between the analyst evaluation and EXCEL approach, the maxima are not considered in the following. Figure 2.1 shows differences between the analyst evaluation and EXCEL approaches for the averages, medians, and minimum values per UT image. Note again for the analyst evaluation approach, the average and median are actually the same values. For the EXCEL approach (because of the column limitations), the average is the midpoint (or average) of the averages of the two halves of the UT image; the median is the midpoint of the medians of the two halves of the UT image; and the minimum is the minimum of the minimum values of the two halves of the UT image.

The differences in the averages, medians, and minimum values are given respectively in the three sections arranged vertically in Figure 2.1. Within each section, the differences are divided horizontally into the three paths mentioned above, then the five plates within each path, and finally the elevations within the paths.

In comparing the top two sections, it can be seen that the analyst evaluation average compares slightly better to the EXCEL median than to the EXCEL average. This would be expected since the analyst evaluation method is actually estimating a median value and not the average. Summary information is given in Figure 2.2. Histograms are included, and towards the top right are standard deviation values. Note that the standard deviation of analyst evaluation to EXCEL differences in averages is about 2.0 mils, while the corresponding value for medians instead has a standard deviation of about 1.1 mils.

Such differences are not considered of practical importance, but note that in Figure 2.2 a statistical test of the mean differences being equal to zero would be rejected (based on the very small significance values labeled Prob $>|t|$ in the t-test information). So the respective means differences of -0.9 and -0.4 mils are statistically significant relative to the variability indicated by their standard deviations. But again, this is of little practical impact.

The minimum values do differ more however with a mean difference of 1.5 mils and a standard deviation of about 5.2 mils. Note that in all these cases a range of about \pm two standard deviations would 
be expected to include most differences. In the case of the minimum values this represents differences of up to about 10 mils. It results from EXCEL including more extreme minimum values from particular pixels or areas in the UT image that have likely been omitted through the expert analyst evaluation. This expert knowledge adjustment of results is likely well justified.

\section{Analyst Evaluation Minus EXCEL Differences in UT Averages}

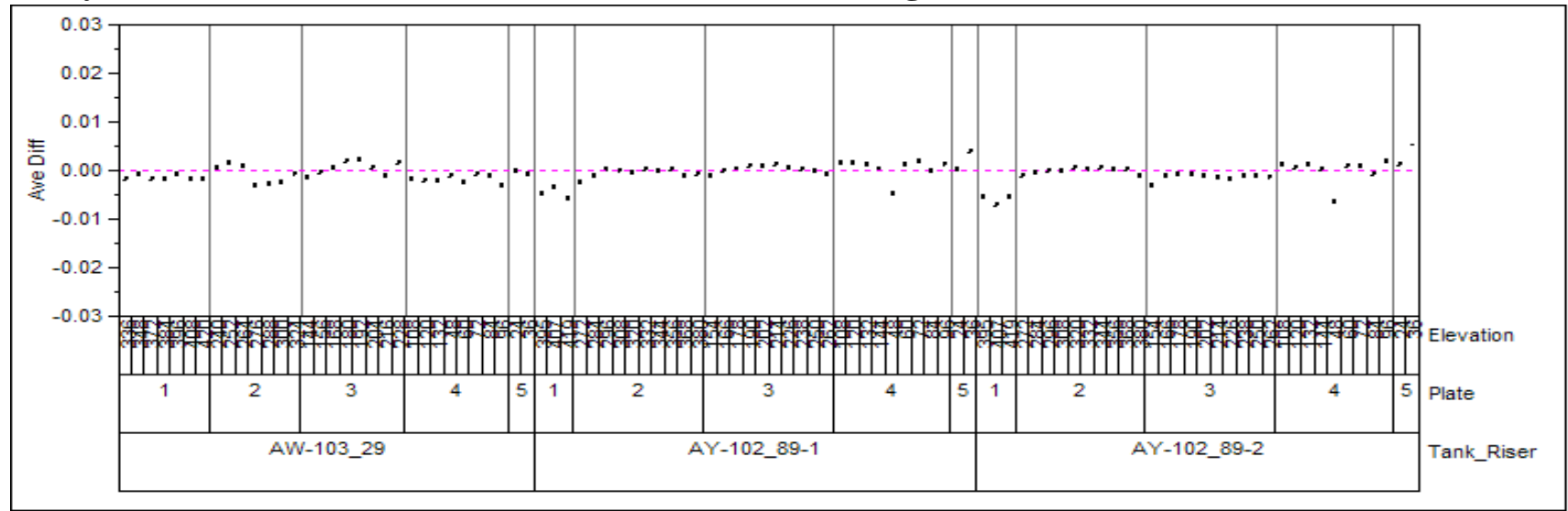

Analyst Evaluation Minus EXCEL Differences in UT Medians

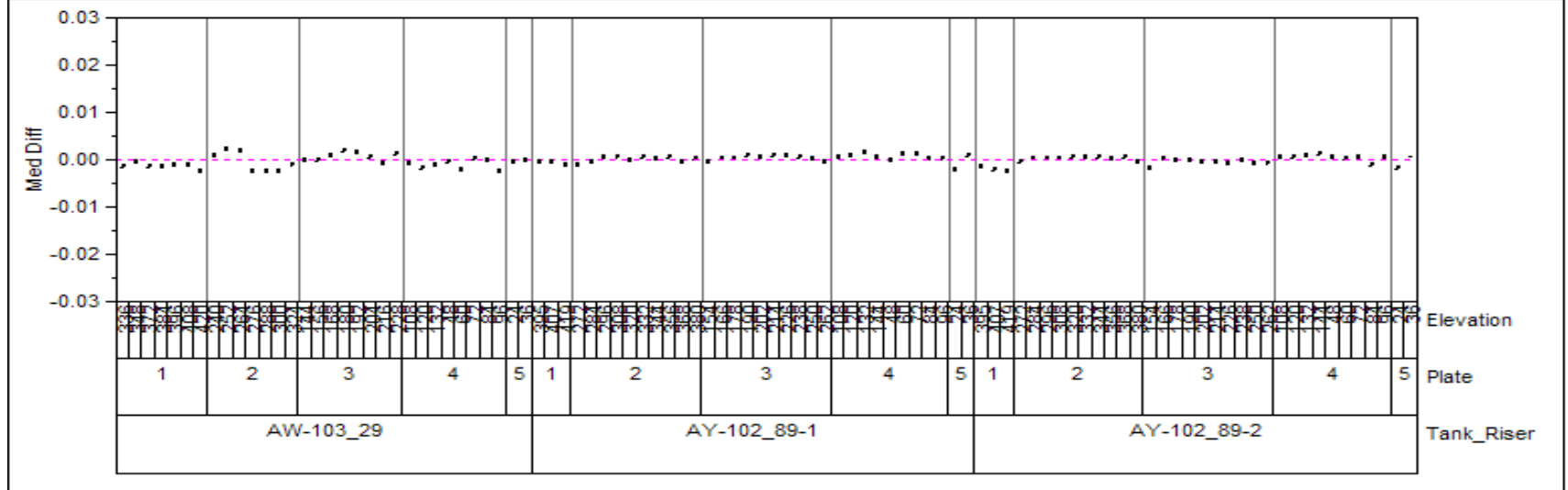

Analyst Evaluation Minus EXCEL Differences in UT Minima

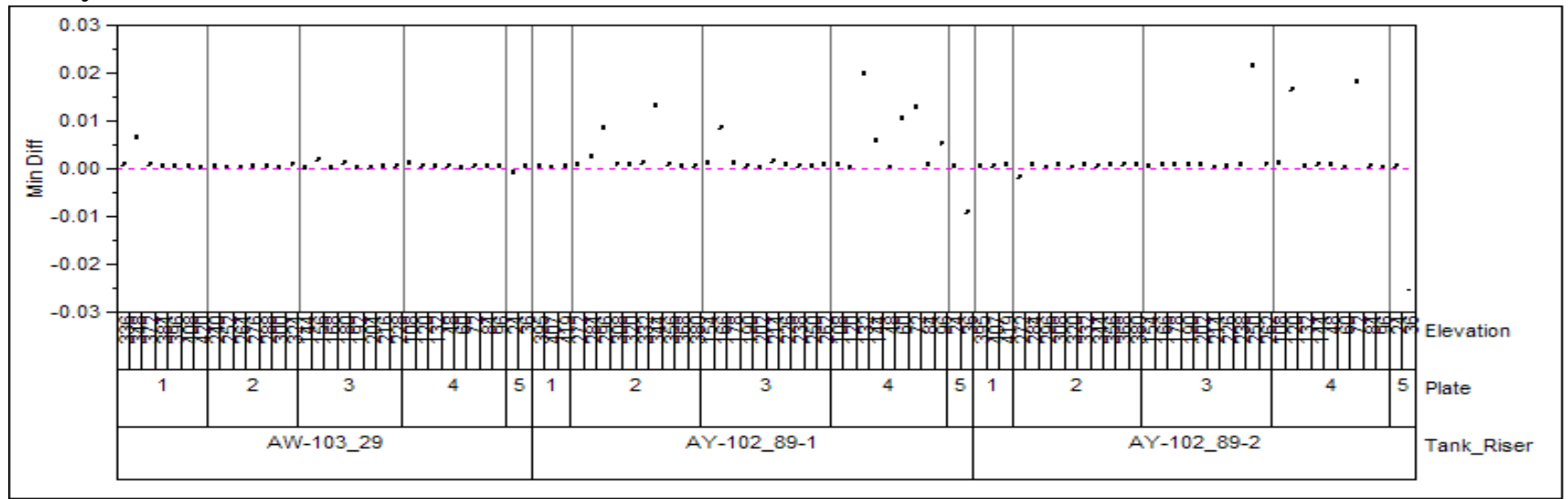

Figure 2.1. Analyst Evaluation Minus EXCEL Differences 
An example of data that would not be considered in the minimum evaluation through expert analyst evaluation would be a lamination in the plate material. A lamination is a separation midwall and would show as a much thinner area than is the case. Laminations are not typically considered wall thinning. The expert can use additional ultrasonic techniques such as angle beam examination to eliminate this anomalous data, whereas the EXCEL data simply reflects the smallest (minimum) data point.

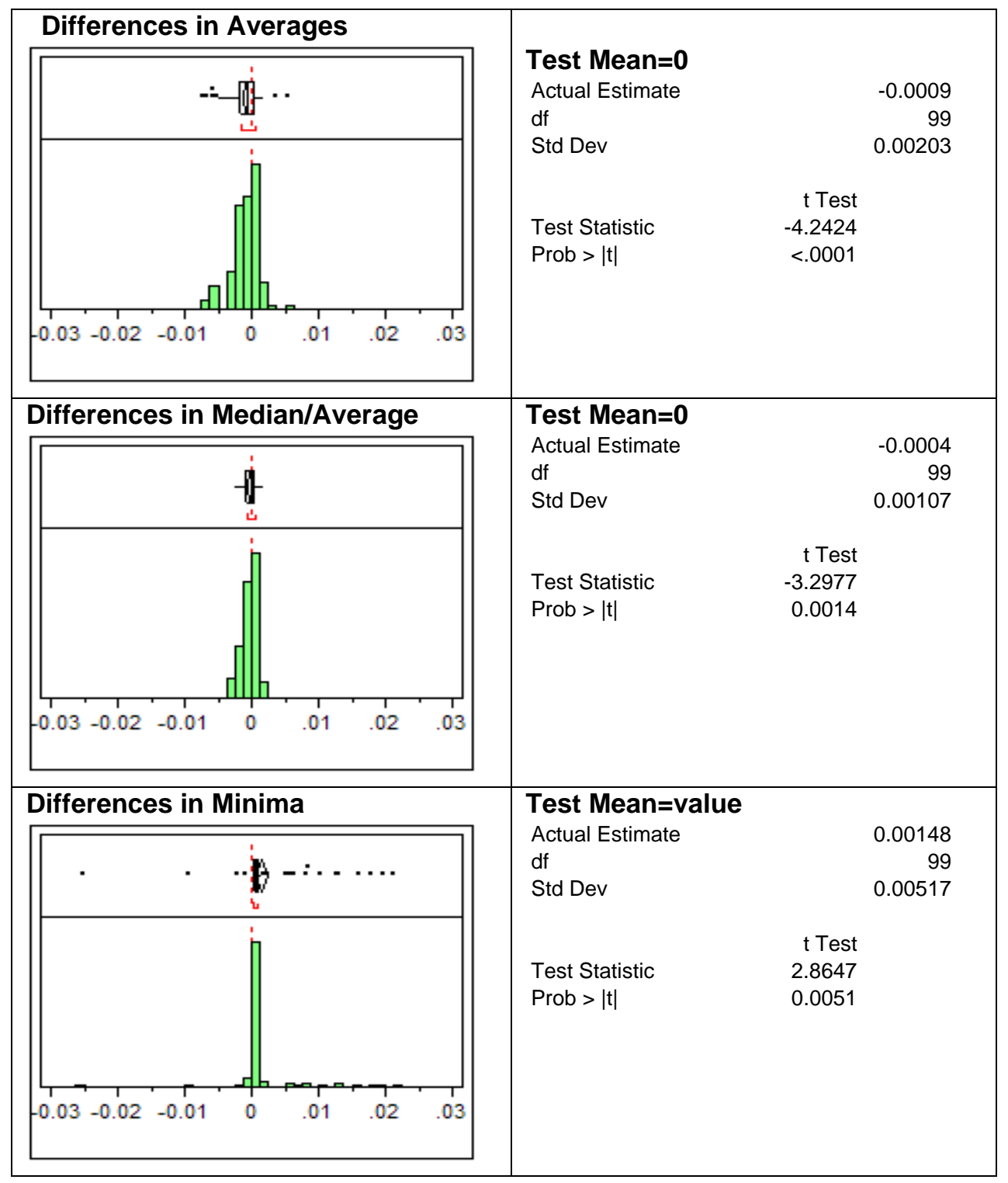

Figure 2.2. Analyst Evaluation Minus EXCEL Difference Summary Results

In summary, little reason is shown for abandoning the analyst evaluation approach. Generally comparable results are obtained through the EXCEL computations, but when substantial differences do occur, it's because the EXCEL approach cannot readily address special anomalous situations that can be 
recognized through the analyst evaluation. However, as stated earlier, a better defined approach for estimating maximum image values, and thereby an original plate thickness and resulting wall thickness loss, is desirable.

\subsection{Operator Qualification Data}

Operator qualification data was analyzed for three test plates. Plates 1 and 3 have milled areas with rounded bottoms (resembling pits) and are somewhat more difficult to measure than Plate 5 which contains flat milled surfaces (resembling general wall thinning). Other test plates include cracks or considerably elongated areas with rounded bottoms, and such plates were not included in theses analyses. Also qualification results performed prior to the year 2000 were not included due to testing differences between then and more recently.

The first row of Figure 2.3 shows all the measurements from test Plates 1, 3, and 5. Results are recorded as differences from the plates' true values which are determined by physical measurements. Values on the horizontal axis of the top left figure are these measurement "errors". On the top right figure, the errors are plotted against the true values on the horizontal axis. Two outliers, one a positive error and one negative, are indicated in these two figures by the darkened points.
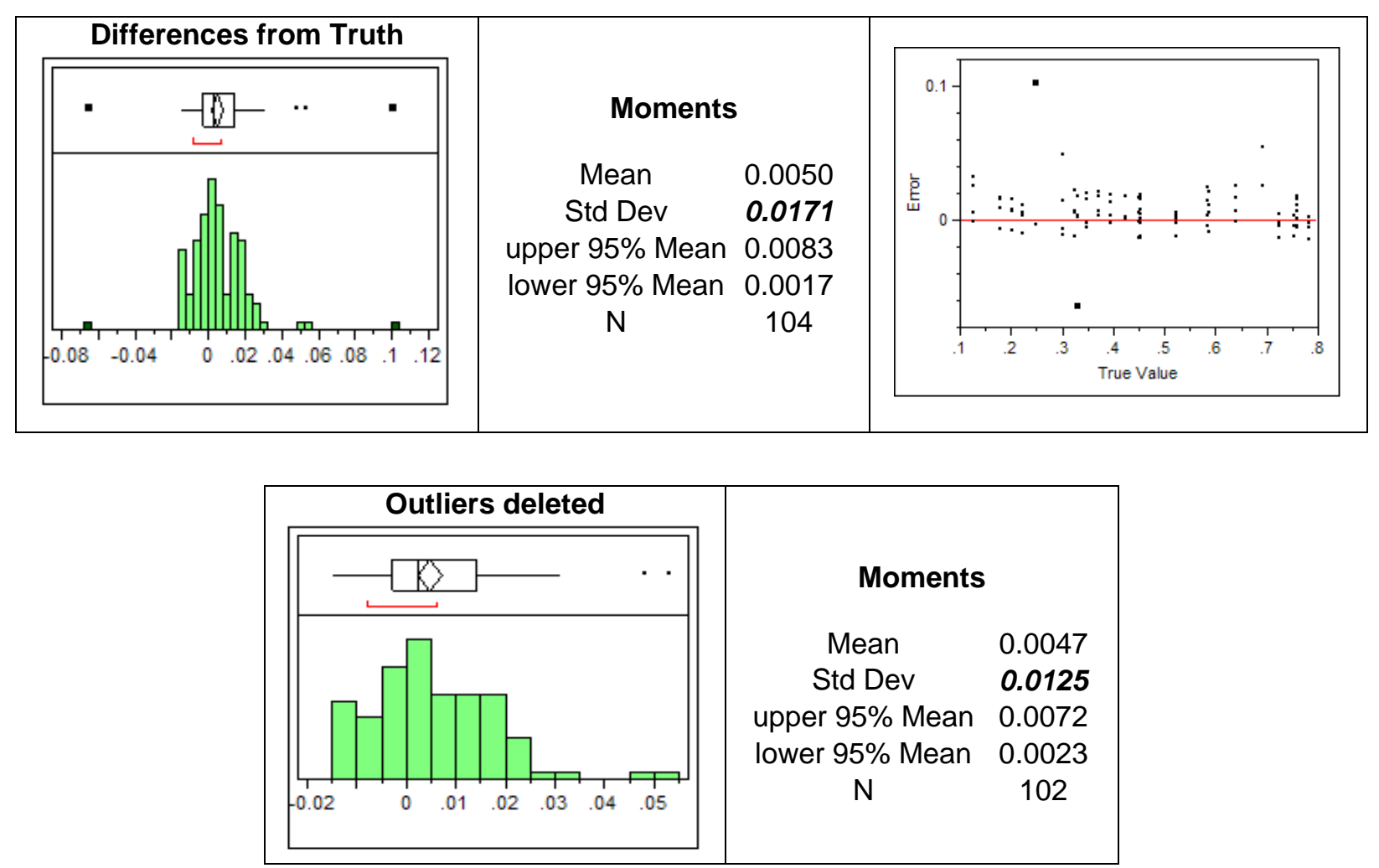

Figure 2.3. Measured Minus True Values from Qualification Data 
With the outliers included, the summary information in the center is obtained. The average difference is 5 mils with the measured values tending to be greater than the true values. But the standard deviation is 17.1 mils. The magnitude of this standard deviation is influenced both by how repeatable the measurements are for a given plate area (or true value), and also by how far off the measured results are from the true values, that is, by how different the errors are from zero. In the top right figure, these are the differences from the red horizontal line.

If the two outlying values are omitted as some type of "special cause" errors and as having undue influence on the summary results, the second row of results is obtained instead. The mean error then becomes 4.7 mils with a standard deviation of 12.5 mils. Thus when one includes both the variability between measurements and the differences from the truth, a + two standard deviation range is \pm 25.0 mils. This can be taken as a measure of the combined precision and accuracy of individual measurements of tank wall measurements if the measurement of the test plates sufficiently resembles the measurement of tank wall thickness. It might be expected however, that even more variability could result in the field.

When one instead considers only repeatability without regard to how close the measurements might be to the "truth", then only the variability within the groups of measurements at each true value are computed. This is illustrated in Figure 2.4. Now only the variability within the red boxes is of interest and not how far the boxes might be from the zero line. Then the standard deviation shown in the table is 11.7 mils. So how consistently the same result is obtained can be considered in the +two standard deviation range \pm 23.4 mils. It can thereby be observed that differences from the truth add little to the uncertainty of measurements. Most uncertainty is due to the lack of repeatability. And of course with tank measurements, we do not have the true values.

\section{Oneway Analysis of Differences By True Value}

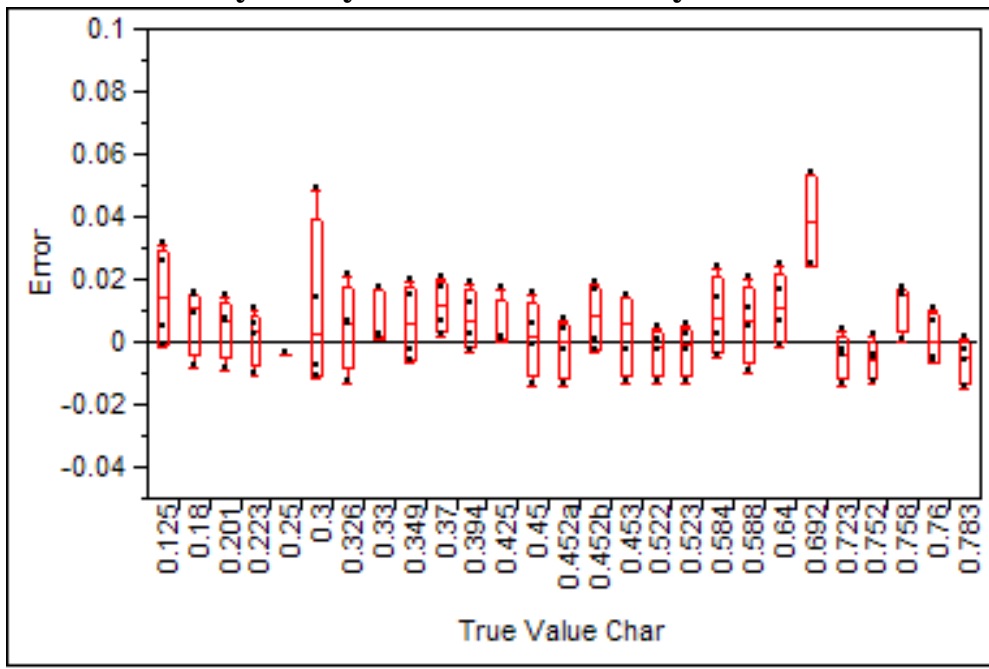

\section{Oneway Anova Summary of Fit \\ Root Mean Square Error Mean of Response 0.0117 Observations

Figure 2.4. Operator Qualification Data Repeatability 
If differences from the truth are considered, qualification data indicates the \pm 25.0 mils range. If only repeatability is considered then the range is \pm 23.4 mils. But note when two measurements are made, the repeatability variance is doubled for their difference, and the standard deviation of their difference is then 1.414 (from the square root of 2) times the standard deviation for a single measurement (this assumes the independence of the measurement errors for the two measurements). The range of differences between two measurements would then be $\pm 1.414 \times 23.4=$ \pm 33.1 mils.

But the previous summary combines both the pitting plates and the thinning plate. The plates are considered separately in Figure 2.5. The RMSE (Root Mean Square Error) values above each plot are the standard deviations which again indicate the repeatability of the measurements. The pit plates show less repeatability with the thinning Plate 5 having the smallest standard deviation of 8.3 mils. Under the assumption that wall thinning dominates the tank wall measurements, the difference between two independent measurements of the same area would then be \pm 1.414 × 2 × $8.3= \pm 23.5$ mils.

Note the interesting pattern for the Plate 5 results where the influence systematic errors can be seen. The thinner plate areas tend to be over- measured while the thicker plate areas tend to be under-measured, but the variability within the groupings tends to be the same throughout. In contrast, the pitting area thicknesses are consistently over-measured. It is not known if these patterns might also occur in tank wall thickness measurements. This systematic error pattern could indicate features of the UT measurement process, or perhaps of the physical method that generates the "true" values for the test plates. 
Pitting Plate 1 (RMSE = 14.9 mils)

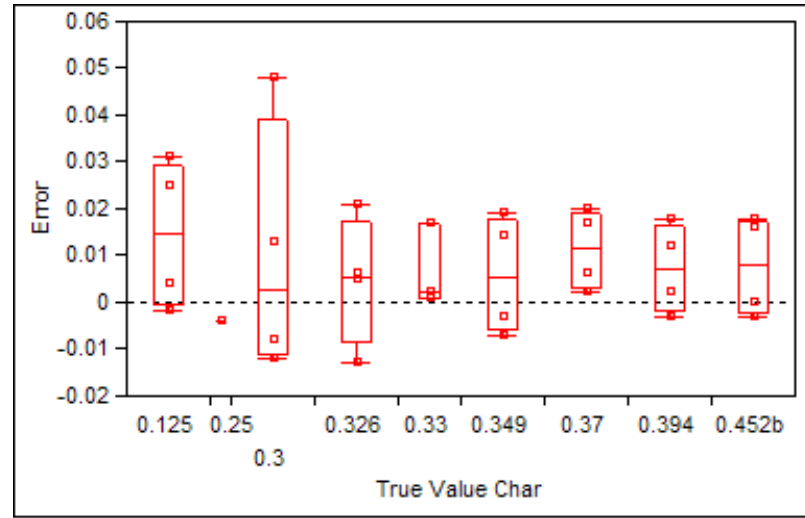

Pitting Plate 3 (RMSE = 11.5 mils)

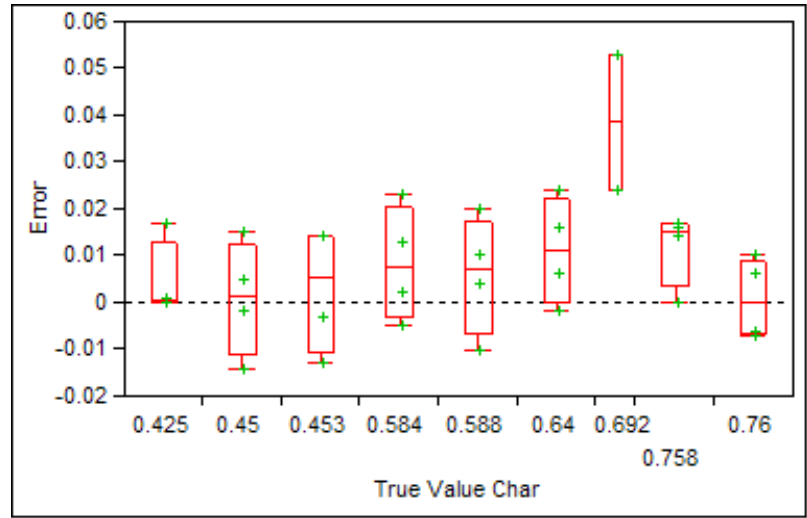

Thinning Plate 5 (RMSE $=8.3$ mils)

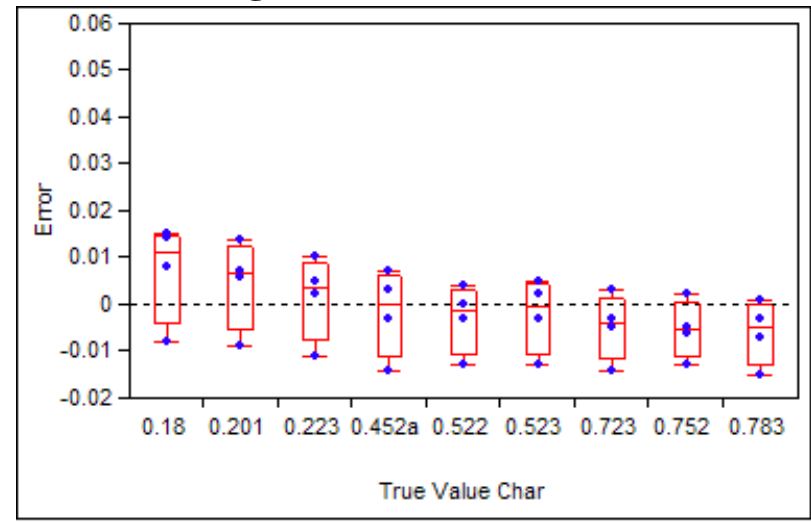

Figure 2.5. Operator Qualification Data Repeatability by Test Plate

\subsection{Adjacent Path Comparisons}

Another source of measurement repeatability is available. If one assumes the wall condition in adjacent UT images, that is at the same elevation in Paths 1 and 2, are actually quite alike, then the measurement of the two images should give comparable results. If there are differences in the areas 
inspected in the two images, then the lack of repeatability should be greater than that observed for the Plate 5 thinning in the previous qualification data section.

The results of comparing each Path 1 image to its adjacent Path 2 image are shown in Figure 2.6. Only five tanks are included since Tank 241-AY-101 had only one path per riser measured by the time this report was written. Only the year 2007 inspection data are included in the figure. Risers are shown within tanks, and then elevation within riser.

Since the top and bottom sections show the UT image averages and minima respectively, and plotted on the same vertical scale, it can be seen that the variability between Path 1 and 2 images is greater for the minima than for the average. This would seem to be intuitively sensible; and since the averages are taken over an entire 12 by 15 -in. UT image, the minimum value repeatability might more closely compare to the minimum value repeatability for the Plate 5 wall thinning test plate reported in the qualification testing.

Figure 2.7 contains means and standard deviations of the Path 1 minus Path 2 differences by tank. The mean values in blue and italics are statistically significantly different from zero over the entire tank and relative to the variability observed within the tank. This is not thought to be of particular importance, but it might suggest that systematic differences can occur between the two measurement paths. This becomes of more interest when the newer 2007 measurements are compared to the older measurements in a later discussion.

The most important values in the Figure 2.7 table are the standard deviations when the path differences are combined over all five tanks. For the path differences in averages and minima these are respectively 6.5 and 10.6 mils. Recall the similar repeatability standard deviation for the difference in two qualification test minimum thickness values for the wall thinning test Plate 5 is 1.414 x $8.3=11.7$ mils. This corresponds to the 10.6 value, which shows fairly good agreement between the repeatability results for the two data sources. It is certainly believable that the wall thickness averages over two adjacent UT tank images would be quite alike and much of their difference attributed to measurement error rather than true plate thickness differences. And the measurement error for an average over larger areas like the UT images would probably be less than that for minimum values. Therefore the 6.5 mils value for the difference in averages is quite reasonable as well.

The 10.6 mils for the difference in adjacent image minima is somewhat surprisingly small. It is actually less than the repeatability indicated by the qualification data, which was 11.7 mils for the difference in two measurements. But the results are certainly comparable with the conclusion being that the measurement methodology carries from the qualification test plates to the field tanks in a very adequate manner. 
Path 1 UT Average minus Path 2 UT Average

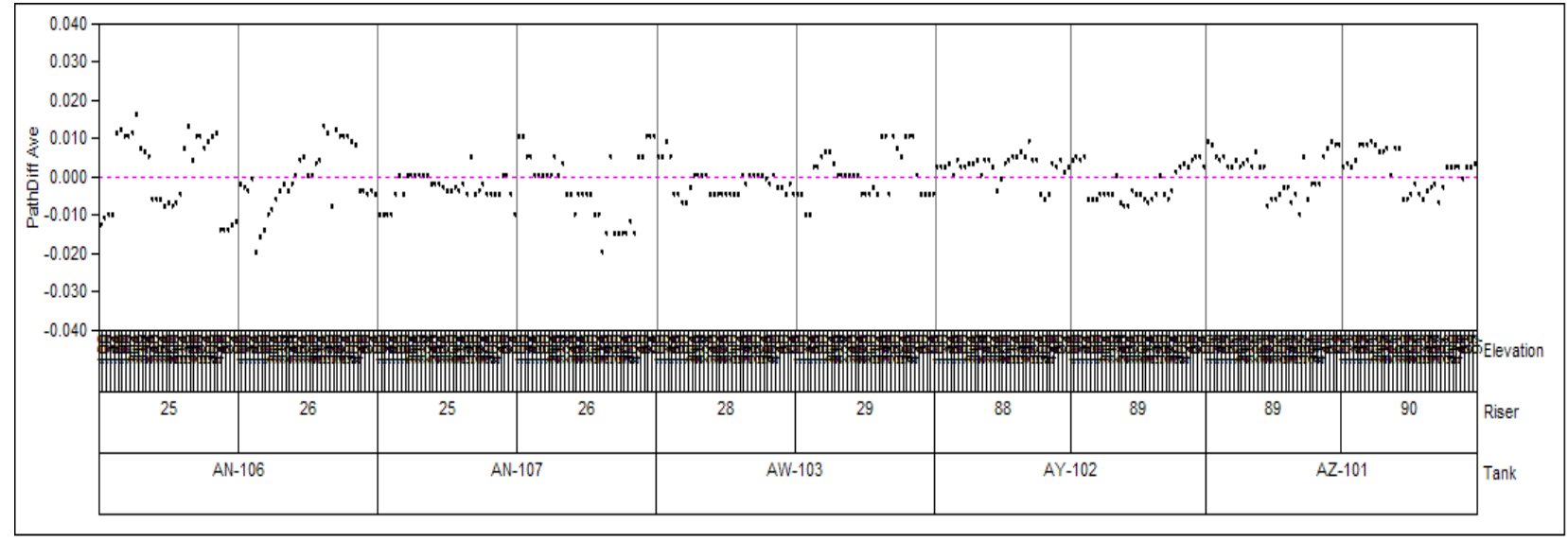

\section{Path 1 UT Minimum minus Path 2 UT Minimum}

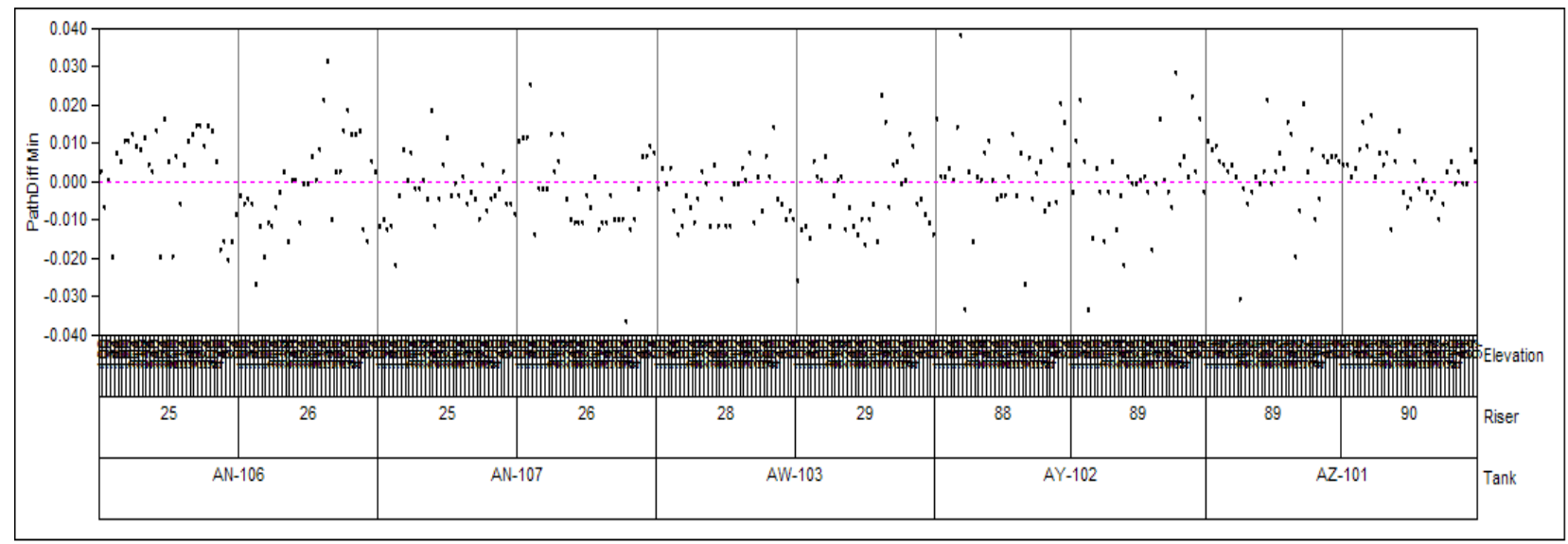

Figure 2.6. Path 1 Minus Path 2 for Adjacent UT Images

\begin{tabular}{|c||c|c|c|c|}
\hline Tank & \multicolumn{2}{|c|}{$\begin{array}{c}\text { Path Differences } \\
\text { for UT Averages } \\
\text { (mils) }\end{array}$} & \multicolumn{2}{|c|}{$\begin{array}{c}\text { Path Differences } \\
\text { for UT Minima } \\
\text { (mils) }\end{array}$} \\
\hline & Mean & StanDev & Mean & StanDev \\
\hline AN-106 & -0.3 & 9.1 & 0.4 & 12.1 \\
\hline AN-107 & -3.1 & 6.8 & -3.0 & 9.6 \\
\hline AW-103 & -0.7 & 5.2 & -4.2 & 8.6 \\
\hline AY-102 & 0.0 & 4.5 & 0.7 & 12.5 \\
\hline AZ-101 & 1.3 & 5.2 & 2.1 & 8.4 \\
\hline Overall & -0.6 & 6.5 & -0.8 & 10.6 \\
\hline
\end{tabular}

Figure 2.7. Path 1 Minus Path 2 Difference Summary Values 
In anticipation of comparing newer inspection results to older inspection results in the following section, Figure 2.8 again shows differences in adjacent UT images, but now the older tank inspections are included as well. It is readily apparent that path differences were much greater in the older inspections. The mean path differences for the various risers are shown by the green lines. They are quite consistently close to zero for the more recent inspections, but they vary pretty wildly for the older inspections. The standard deviations of 6.5 and 10.6 mils in the last line of the table above respectively become 14.5 and 15.1 mils for the older measurements. But this overall greater variability in path differences is not so much the issue as is the systematic differences between paths down a riser. The systematic difference tends to last along the entire vertical length of the measurement paths.

Current measurement convention results in a return to the tank for re-inspection of a path when it does not match its adjacent path. The path with larger wall thickness values is typically re-inspected with the new results described as usually falling much closer to the other path that had smaller values. Should this not be the case, the path with smaller values is instead re-inspected as well. But in this manner, the improved closeness in path measurements results for the new inspections as shown in Figure 2.7. Considered as a quality assurance tool, this insistence in satisfying a rather informal "closeness" criteria between the two paths certainly reduces the variability in path to path images, and it hopefully improves the measurement accuracy as well.

Unfortunately this brings into question the comparison of the old and new inspections that would be done to examine the changes in tank walls. The measurement approach has fundamentally been changed due to the new re-inspection decisions. It is assumes that this re-inspection is an improvement in obtaining good estimates of current tank wall thickness. But that brings into question the impact of the systematic path differences that were tolerated without re-inspection in the older inspections. Sometimes such systematic path differences would result in over-reporting remaining wall thickness while other times it would result in under-reporting instead.

This makes it difficult to compare old and new inspections for corrosion evaluation purposes. Certainly a more consistent measurement approach should be applied to avoid this problem. But with inspections on a particular tank up to a decade apart, ongoing measurement improvements over that long a period might continue to complicate the comparison between old and new. But none-the-less the old minus new inspection results differences are shown in the next section. 
Path 1 UT Average minus Path 2 UT Average

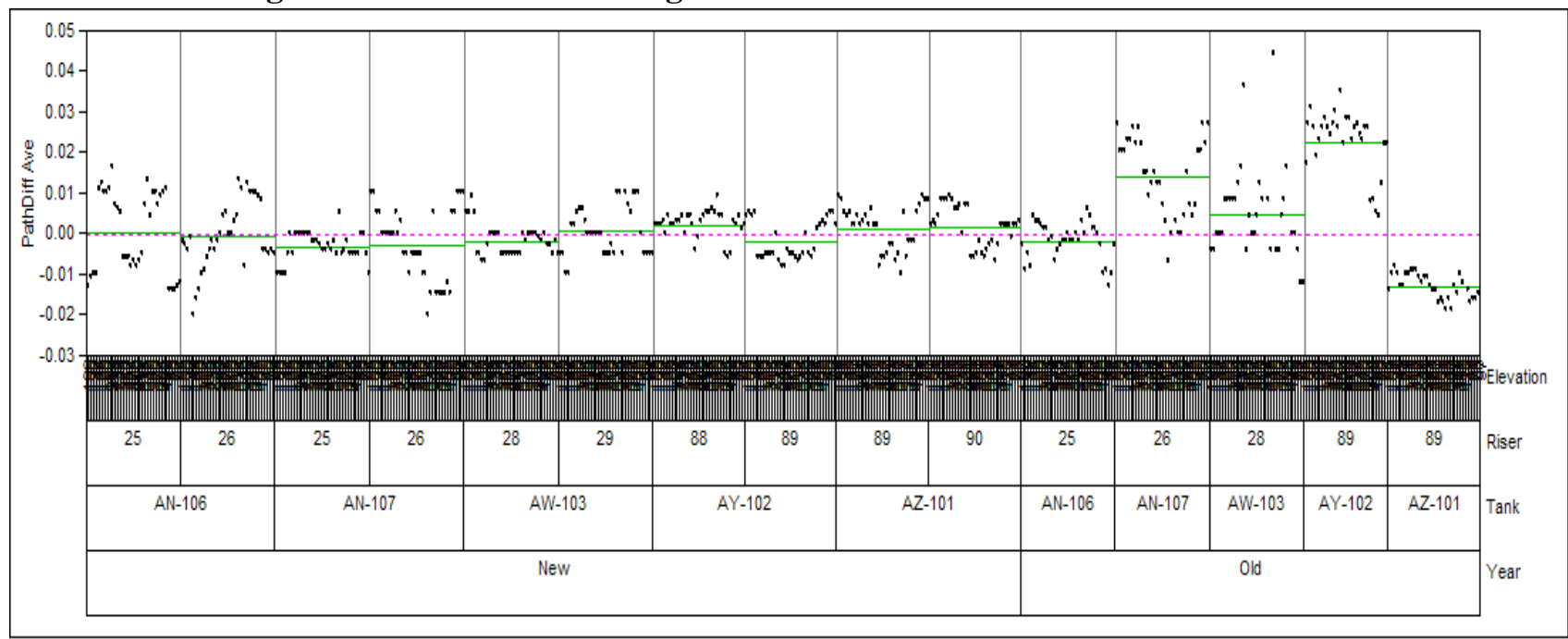

\section{Path 1 UT Minimum minus Path 2 UT Minimum}

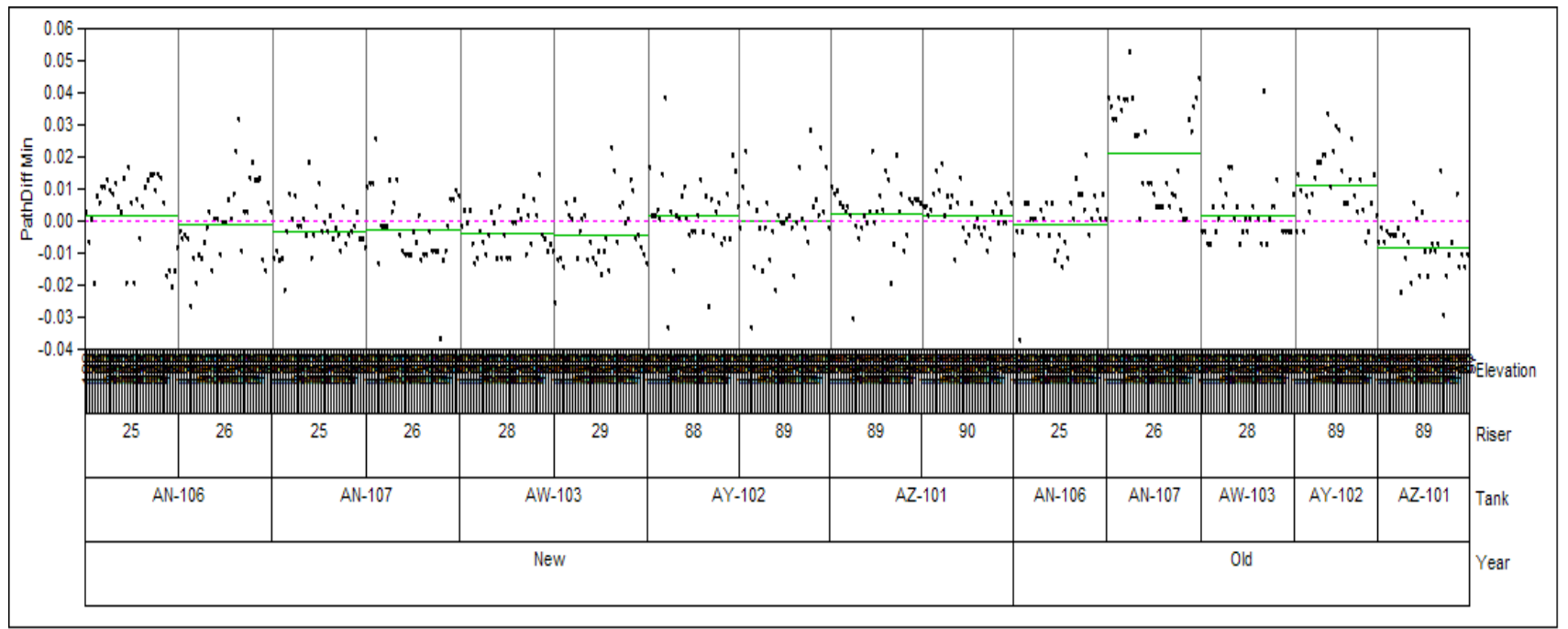

Figure 2.8. Path 1 Minus Path 2 Including Old Inspections 


\subsection{Old Inspection versus New Inspection Comparison}

The reader should be cautious in making corrosion conclusions based on the data contained in this section due to the measurement issue raised in the previous section. Systematic differences between paths now result in re-inspection in the newer inspections, but those differences were left unresolved in the older inspections. This revised "quality assurance" convention is thought to make the new inspections more accurate in estimating the true remaining wall thicknesses, but resulting differences from the older results might then result from the differing measurement re-inspection conventions as opposed to accurately showing actual changes in the tank wall thicknesses. If such systematic differences between paths occurred in the old inspections, as illustrated in Figure 2.8, one has to assume that indeed in some cases both paths could systematically differ from the true wall thickness. With more accurate current measurements due to re-inspection, "old minus new" differences would therefore not necessarily reflect the true changes in wall thickness.

Another source of systematic error between old and new inspections could be the effects of temperature and velocity on the measurement of wall thickness. An estimate of the velocity of sound within the tank wall is a required input into the UT data acquisition system. Typically the sound velocity is input from a table value for a material that is compositionally the same as the material under inspection. The value entered in the old inspection was not the same as was entered in the new inspection and no compensation factor was used to account for the temperature variations between the tank wall and calibration standard. These effects can account for slight changes in the measured wall thickness. Persistent temperature differences between old and new inspections, and even between new and new inspections, could result in potential differences in the 0.003-in. to 0.008-in. range; but a more rigorous investigation is needed to ascertain the true impact. Additional efforts are underway to identify and explore these additional sources of variability.

None-the-less a comparison of old to new measurements would seem to be an essential use of the data available. And although a wall thickness "change" is computed in the following, it is unknown how much of such change is real and how much is due to systematic differences in the way the tanks were inspected. The reader can refer to recent work on corrosion rates based on coupon studies.

Figure 3.1 shows the differences in old inspection and new inspection UT averages and minimum values for those UT images that include approximately the same tank wall areas in each inspection. For each tank, only measurements from the same riser in both the old and new inspections are used. Paths 1 and 2 are located at approximately the same point for the riser for both the old and new inspections, and the same 12 inch vertical steps of UT images are maintained in each inspection as well. In this manner the UT images can be paired from the old and new inspections with reasonable confidence that primarily the same tank area was inspected within the paired UT images on each occasion.

The Figure 3.1 "old minus new” differences for the averages and minima are given respectively in the top and bottom sections of the figure. Within each section results are divided by tank, by riser within tank (in the case of AY-101), by path within riser (except for AY-101), and by elevation within path. The green horizontal lines indicate the mean "change" from the old to new inspections for the average and 
minimum thickness for each path. Note that in comparing Figures 3.1 and 2.8, the path differences in Figure 2.8 can be seen to influence the relative old minus new differences by path in Figure 3.1.

Old minus New difference summaries are given in Figure 3.2, but again it is unclear if the differences are due to actual wall thickness changes or instead due to systematic differences resulting from the change in the measurement process with respect to the re-inspection of "unlike" paths.

Old Minus New UT Averages

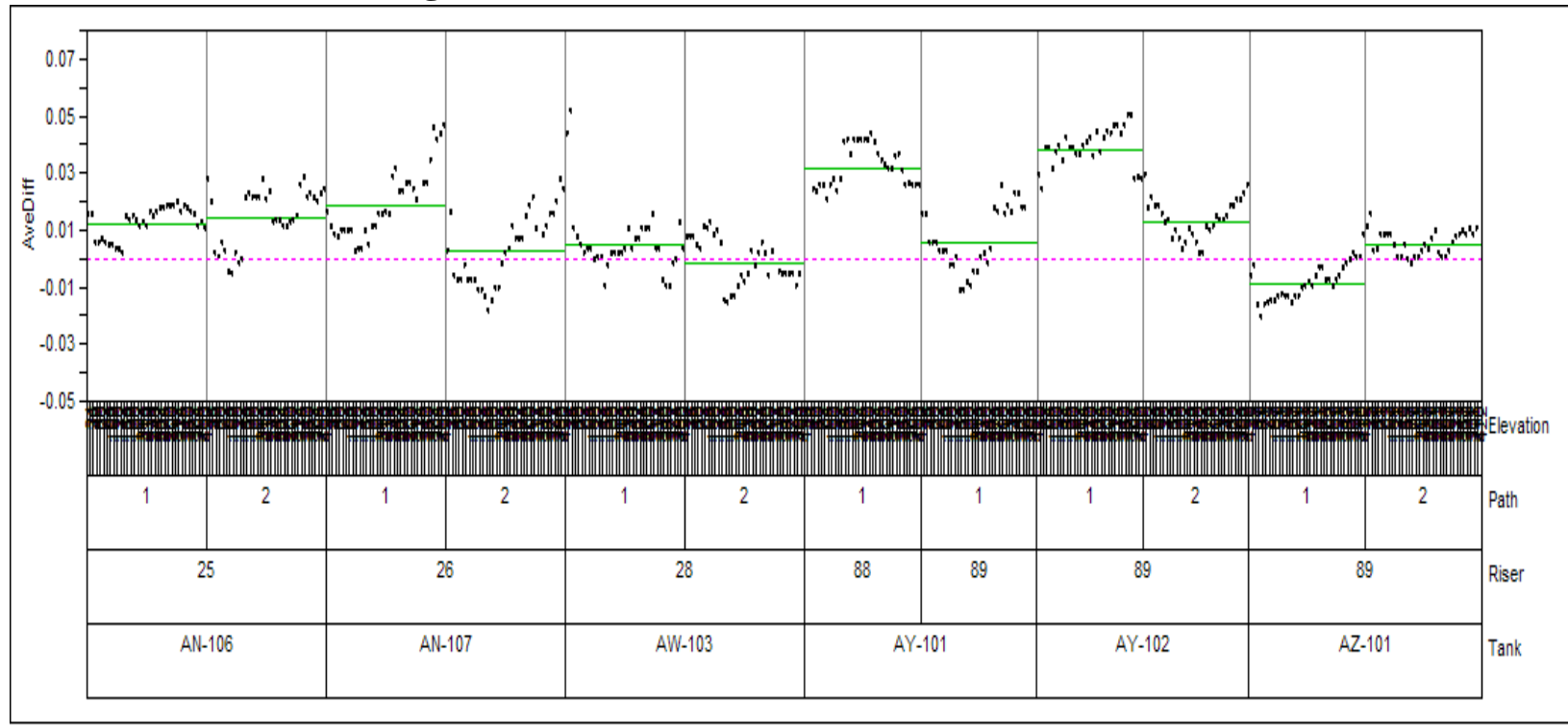

\section{Old Minus New UT Minima}

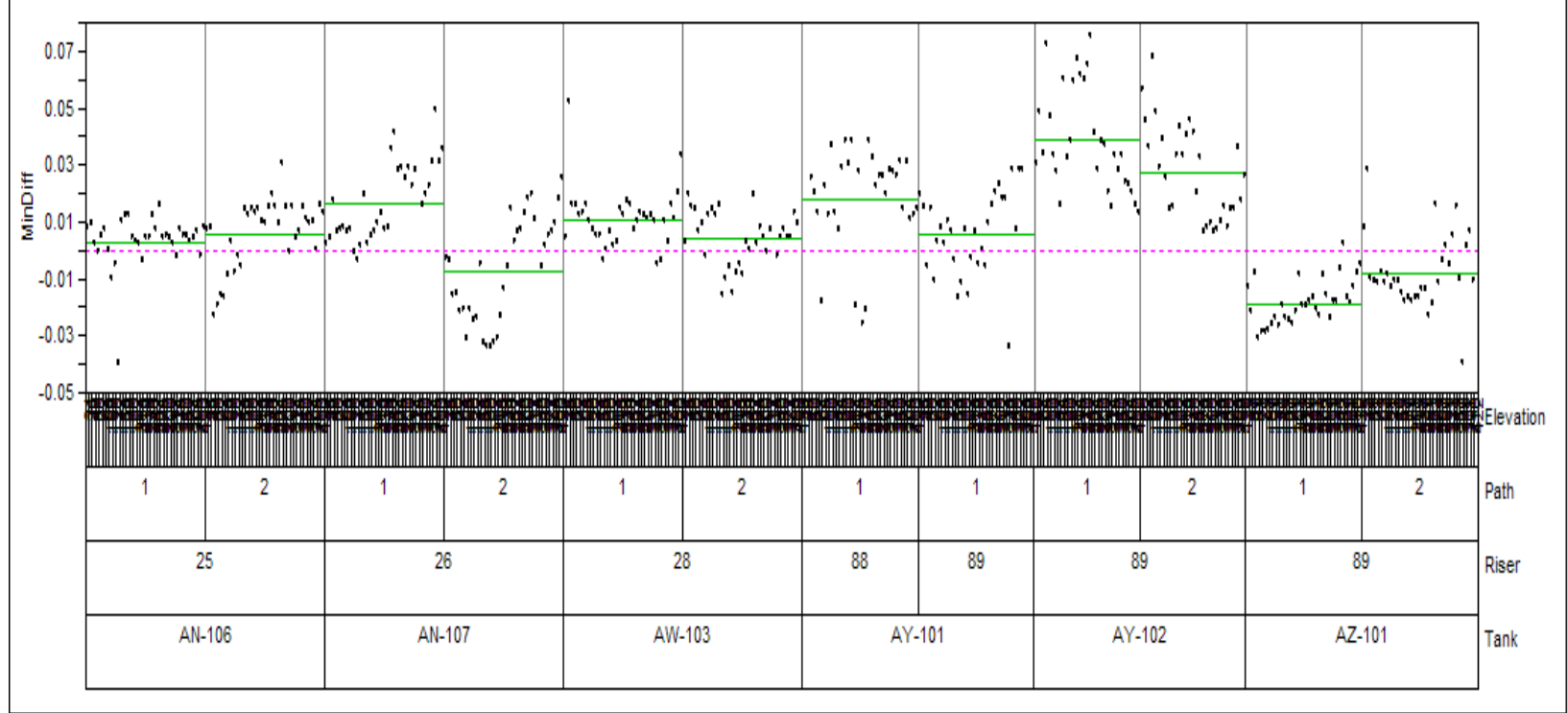

Figure 3.1 Old Minus New Differences for UT Images 
Figure 3.2 gives the mean of the old minus new UT average and minima differences by tank; green diamonds represent confidence intervals for the means. Results are mixed with some tanks showing no change, others showing considerably thinner walls (up to 40 mils), but with AZ-101 actually showing wall thickness gains. As discussed earlier, it is feared these results might be driven more by systematic differences between paths due to differing re-inspection practices than they are by actual wall thickness changes that might have occurred between the two inspections. The measurement process should be kept as consistent as possible between old and new inspections to avoid this type of situation.

UT Averages

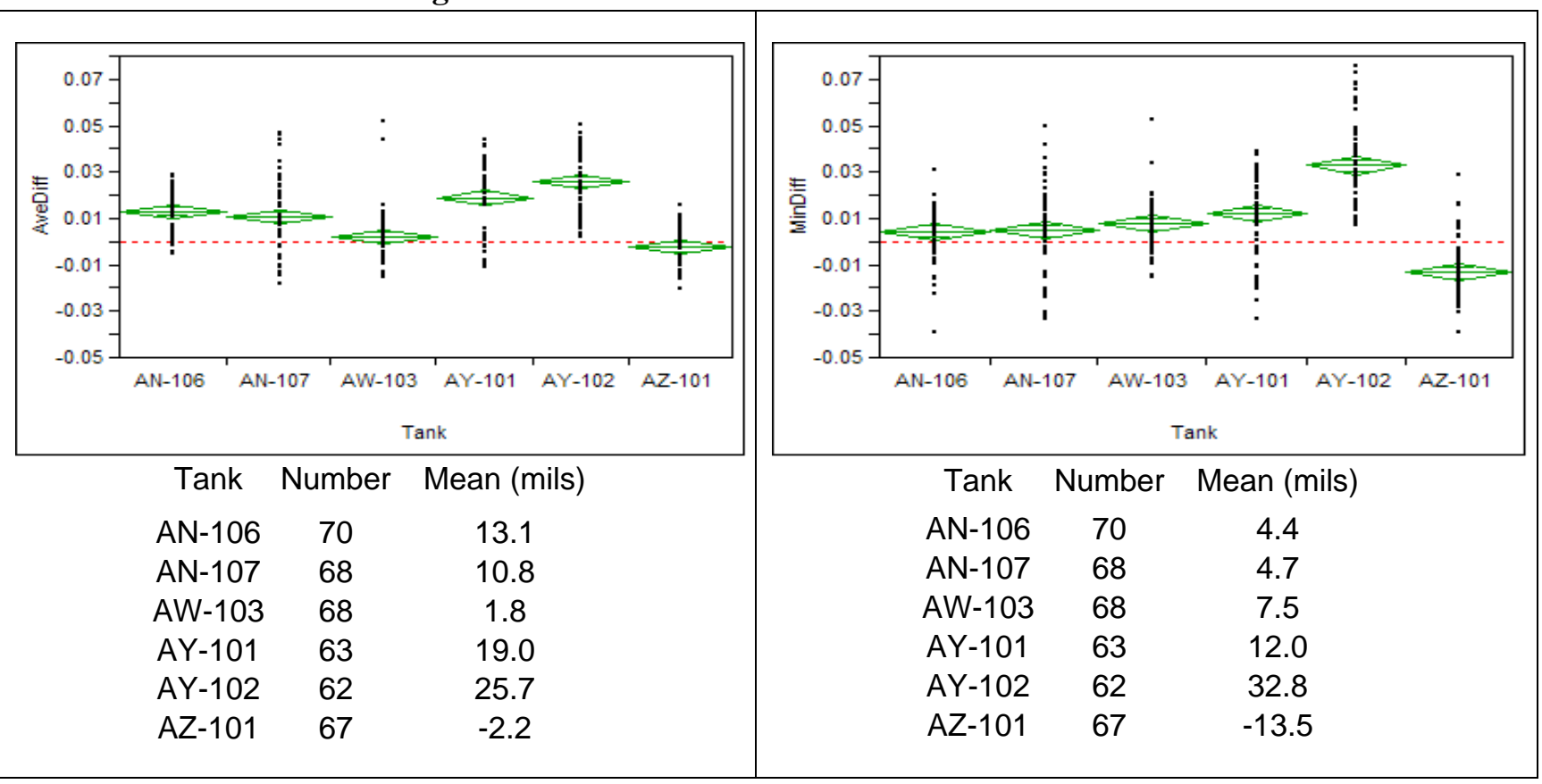

Figure 3.2 Old Minus New Differences for UT Images by Tank 


\subsection{Riser Differences}

Current wall thickness inspections consist of two paths down each of two risers. The use of two risers resulted from earlier work that indicated wall thickness obtained using a particular riser might not be completely representative of what would have been found using a different riser. The only data available to address such riser differences came from the 2001 inspection of Tank 241-AY-101 which had measurements taken using four different risers. The Weier, Anderson, \& Berman (2005) report on riser differences in that tank suggested that if only a single riser were to be used on subsequent tank inspections, an additional one-sigma uncertainty of 10 mils should be incorporated into extreme wall thickness estimation results to accommodate potential riser differences.

Rather than using that single riser approach however, the decision was made to use two risers in subsequent inspections, thereby allowing riser differences to introduce more variability into the measurement results. While this decision was based on the 2001 study, it can be seen in the following analyses that such riser differences are not shown in the more extensive set of tanks that now have inspections completed for multiple risers.

Recall for the individual tank reports, extreme value analysis used "estimated maximum loss" for each UT image by estimating a plate nominal thickness from the plate/riser UT image maximum values. That same approach is used to examine riser differences by using such estimated maximum losses. The results are displayed in Figure 4.1 by tank, by riser within tank, by plate within riser, and by elevation within plate. Short vertical lines in the figure connect the two results obtained in each case from the two paths down a riser; only single points are available for Tank 241-AY-101 since only a single path was used down each of the two risers.

A variance components analysis was performed on these estimated maximum losses to determine how much they varied between tanks, between risers, between plates, between elevations, and between paths. The results are given in the table at the bottom of the figure. The final line in the table is the total variability in the measurements indicated by a variance of 0.00041369 . The terms above this quantity give the variances associated with the various sources; summing them gives that total variance. The next column shows these variances as a proportion of the total, and these proportions are also displayed by the colored bars.

The final column then gives the square root of the variances, that is, the standard deviations, associated with each source. Note the standard deviations do not sum to give the total standard deviation. The biggest source of variability is between plates with $47.4 \%$ of the total variability and a standard deviation of 14.0 mils. One should be concerned that the cause of this much variability between plates might well be due to the estimation of a beginning nominal value from which to compute the estimated losses. For this reason a more formal approach to estimating UT image maximum values and how to use them to establish an initial plate thickness is quite desirable.

The other sources of variability contribute less, and most notable is the zero variance contribution from riser differences. This was certainly not the case in similar analyses of the 2001 Tank 241-AY-101 
data. But note throughout the figure the comparison between two risers within a tank; the best example is perhaps Tank 241-AY-102. Note how the pattern of points is largely the same across the plates for the two risers. That similarity between risers pretty much holds across all of the tanks. That is why no variance is indicated between risers, at least not relative to the variability between the plates within the risers, and this suggests that in subsequent inspections, using multiple risers likely need not be required.

\title{
Variability Chart for Estimated Maximum Loss Per UT Image
}

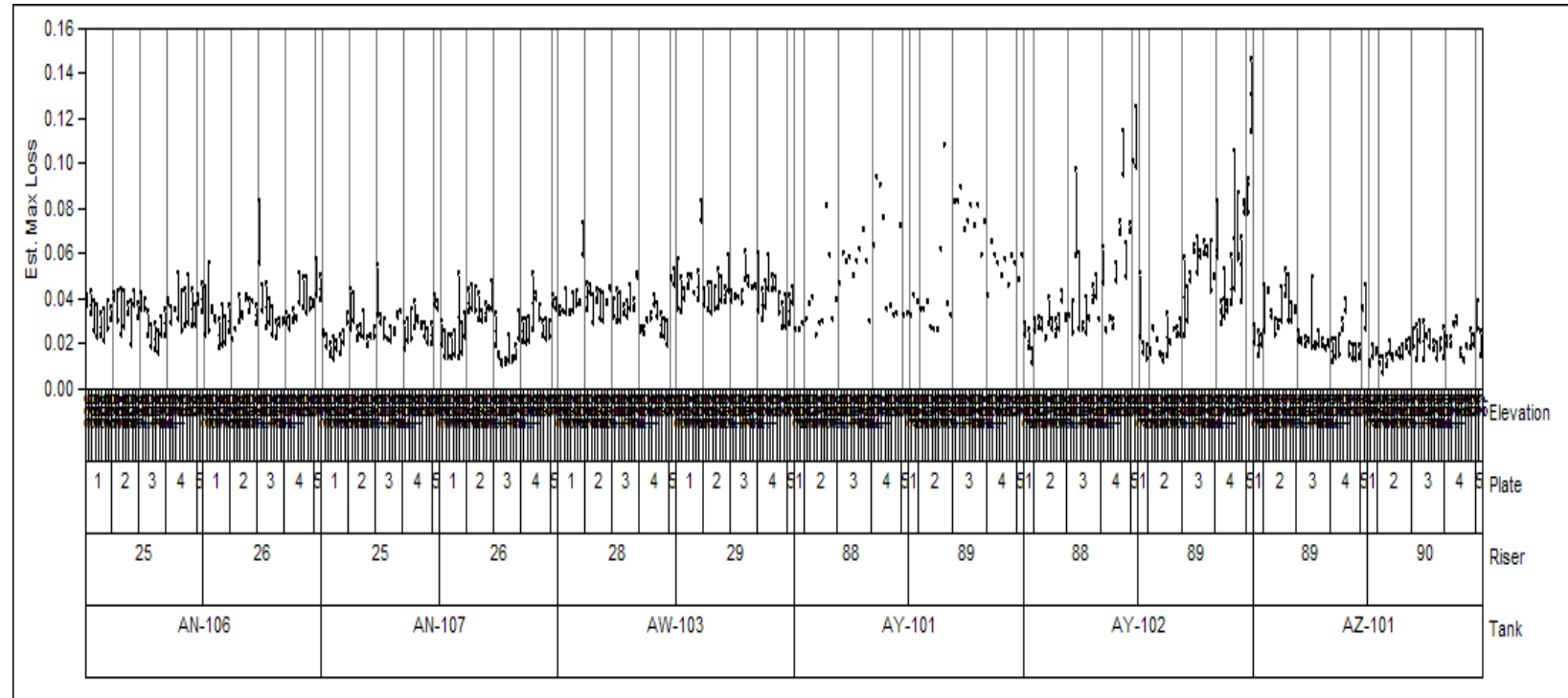

\author{
Variance Components \\ Component \\ Tank \\ Riser[Tank] \\ Plate[Tank,Riser] \\ Elevation[Tank,Riser,Plate] \\ Within/Path \\ Total
}

$\begin{array}{cc}\text { Var Component } & \text { \% of Total } \\ 0.00009490 & 22.9 \\ 0.00000000 & 0.0 \\ 0.00019599 & 47.4 \\ 0.00005559 & 13.4 \\ 0.00006721 & 16.2 \\ & \\ 0.00041369 & 100.0\end{array}$

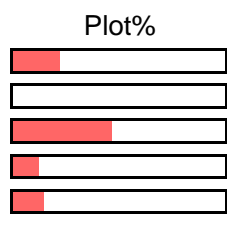

Sqrt(Var Comp) Mils

9.7

0.0

14.0

7.5

8.2

0.00041369

20.3

Figure 4.1 Variance Component Analysis for Examination of Riser Differences

Also note while considering Tank AY-102, the extreme differences between plates. This also occurs for Tank AY-101. These two tanks generate the plate variability that is shown to be the greatest variability source. That isn't really the case for the other tanks however. Figure 4.2 separates those two tanks and does the variance component analysis separately for the two tank groupings.

Without those two tanks, the main sources of variability are tank and path, followed then by plate; this is shown in the top section of Figure 4.2. In the bottom section with only the two AY tanks included, plate is the dominant source of variability with almost $65 \%$ of the total variability. One sigma for plates for these two tanks is 22.3 mils while for the other tanks it was only 5.4 mils. 
Variance Components without AY-101 and AY-102

Component

Tank

Var Component

$\%$ of Total

$0.00005656 \quad 37.6$

Riser[Tank]

Plate[Tank,Riser]

Elevation[Tank,Riser,Plate]

0.00000291

1.9

$0.00002902 \quad 19.3$

Within/Path

0.00001096

7.3

0.00005089

33.9

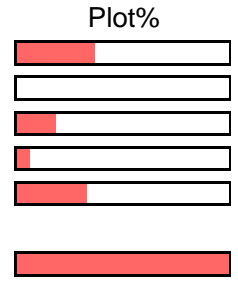

Sqrt(Var Comp) Mils

7.5

1.7

5.4

3.3

7.1

Total

0.00015034

100.0

12.3

Variance Components for only AY-101 and AY-102

Component

Tank

Riser[Tank]

Plate[Tank,Riser]

Elevation[Tank,Riser,Plate]

Within/Path

Total

Var Component

0.00000000

0.00000000

0.00049632

0.00016291

0.00011110

0.00077033
$\%$ of Total

0.0

0.0

64.4

21.1

14.4

100.0

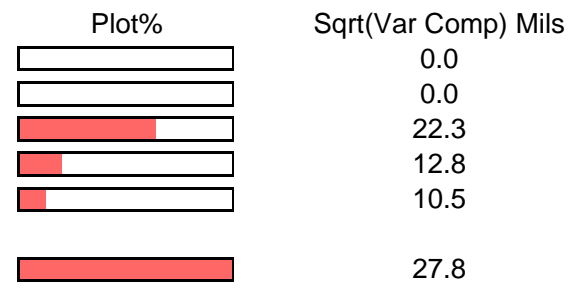

Figure 4.2 Variance Component Analysis with and without Tanks AY-101 and AY-102

But most importantly, in either case, riser variability does not contribute at all. There appears to be little reason to continue the multiple riser requirement for tank inspections. More paths down a single riser would likely offer better information. And if the systematic differences between paths that influence the older inspections continue to occur, the needed re-inspections will be more readily identified when 3 or 4 paths have been inspected down the single riser. 


\subsection{Conclusions and Recommendations}

Evaluation of the wall thickness measurement results for six tanks inspected in 2007 and previously inspected between 1998 and 2001 leads to the following conclusions and recommendations.

\subsection{Measurement Precision and Accuracy Topics}

The following three precision and accuracy topics (i.e., Inspector UT determination versus computer data analysis, Variability of UT results from Qualification Testing, and Adjacent Path assessment) were evaluated resulting in the conclusions listed. Additional topics, such as UT differences on rusted versus cleaned surfaces, repeated DST UT scans, and affect on repeatability from UT equipment and calibration block temperatures versus tank temperature, etc.; will be added in revision 1 to this report.

\subsubsection{Analyst Evaluation of UT Data versus EXCEL Spreadsheet Evaluation}

Based on direct comparison of the analyst evaluation results of UT images and the computer evaluation of EXCEL spread sheets, many reasons are noted for keeping the analyst evaluation approach. Generally comparable results are obtained through the EXCEL computations, but when substantial differences do occur, it's because the EXCEL approach cannot readily address special anomalous situations (e.g., lift-off and touch down errors, material laminations, noisy data, etc.) that can be recognized by a trained analyst. Continuation of the analyst evaluations is recommended.

However, within such analyst evaluations, standardizing the estimation approach for maximum values per UT image is recommended. In turn, an appropriate method for using such maximum values over a plate/riser combination, to obtain an actual plate thickness, should be established. This actual plate thickness value is needed to compute wall thickness losses, which are used in extreme value statistical estimation where measured losses can be statistically combined across several plates or plate courses. Under current inspection and analysis methodology, variability between plates is indeed one of the most prominent sources of variability in estimating wall thickness loss; this is most likely due to not knowing the actual starting thickness (versus nominal thickness) of the various plates. The large variability likely stems from the estimation of original thickness from drawing specifications, rather than in the measurement of the current remaining wall thickness.

\subsubsection{Operator Qualification Data Examination}

Minimum thicknesses are reported by the UT operator in UT qualification testing for pitting and thinning test plates. When this data for both thinning and pitting is statistically combined (includes test Plates 1 and 3 (pit plates), and 5 (thinning plate)), and when one considers both the repeatability between measurements of a specific test plate area, and the differences from the "true" thickness of that area; then $\mathrm{a} \pm$ two standard deviation uncertainty range for a single measurement is \pm 25.0 mils. For repeatability only, without regard for the accuracy in matching the true values (again for pitting and thinning plates 
combined), the \pm two standard deviation range is \pm 23.4 mils. It can thereby be observed that differences from the true value add little to the uncertainty of measurements, and most uncertainty is due to the lack of repeatability

If we consider the thinning Plate 5 alone, the \pm two standard deviation range is reduced to \pm 16.6 mils. This is probably the best measurement uncertainty range that might be applied to the typical minimum UT image wall thickness for tank inspections if indeed the testing capability of tanks in the field is comparable to the qualification results (i.e., we have not yet explored the effect of surface condition).

Note however that the uncertainty of a single measurement will not typically be the driver in decision making. Rather the mean over many such measurements will be of importance, and the uncertainty associated with the mean of multiple measurements will decrease from the individual measurement uncertainty as the number of measurements increases. In addition, the difference between two independent measurements would often be of interest, and then the variance of the difference in the measurement (assumed with independent error) would be doubled with the standard deviation of the difference increased by a factor of the square root of two as in $\pm 1.414 \times 2 \times 8.3= \pm 23.5$ mils. So for any two measurements of minimum wall thickness to be considered different from each other, their difference would have to fall outside that range.

\subsubsection{Adjacent Path Comparisons}

At the time of this revision 0 report, there are no directly repeated measurements in the tank inspections with which to examine measurement repeatability. The closest we can come is by comparing adjacent UT images from adjacent paths under the assumption that the tank area is actually quite similar in these two areas. This was done by comparing Path 1 and Path 2 adjacent images over all the 2007 tank inspections. The resulting \pm two-sigma difference range was \pm 21.2 mils. This is somewhat surprisingly small. It actually shows better repeatability between the minimum thickness in adjacent tank areas to be less than the repeatability indicated by the qualification data ( \pm 23.5 mils) for the difference in two measurements. But these results are certainly comparable with the conclusion being that the measurement methodology carries from the qualification test plates to the field tanks in a very adequate manner.

As already stated, there may be little value in characterizing the repeatability, or measurement error, associated with a single measurement, or in the difference between two measurements. Rather the mean over many such measurements, or more specifically, the mean over many differences in measurements, should be evaluated relative to the standard deviation shown over the many such measurements to determine their statistical significance.

\subsection{Old Inspection versus New Inspection Comparison}

Unfortunately, changes in re-inspection practices when adjacent paths are found to show an offset in results bring into question the value of comparisons of the old and new inspections to examine the 
changes in tank wall thicknesses. The measurement approach has fundamentally been changed from the original baseline UT data, due to the new re-inspection decisions that attempt to eliminate significant/unexpected offsets between the paths, by immediate re-inspection. This was not done in the older inspections, and path differences are apparent in those measurements.

It is feared that the results of old minus new comparisons are driven more by such systematic differences between paths in the older inspections. Current re-inspection is thought to give more accurate wall thickness results. Since the systematic path differences were left alone in the older data, it can certainly be the case that both paths could indeed somewhat systematically differ from the truth, and then comparison to current more accurate results don’t truly show actual changes in wall thickness.

Old to new comparisons were done in any case in this report, with the caveat that differences might be due to changed measurement methodology rather than actual wall thickness change. In so doing, some tanks show wall thickness loss, some show no change, and some show wall thickness gain. Presently, the UT methodology for wall thickness "loss" is not considered reliable since either 1) new measurements have to be compared to questionable original nominal wall thickness or 2) new measurements have to be compared to old measurements that might differ since path re-inspection conventions have changed. Instead separate corrosion loss determinations are being done by established electrochemical determination from actual waste (Duncan 2007). The UT measurement process should be kept as consistent as possible between old and new inspections to avoid this type of situation. And it is also noted that for corrosion studies, it is very desirable to continue to return to the same riser/path/UT image locations as was done for the old and new inspections examined in this report.

\subsection{Riser Differences}

Two risers were inspected per tank in 2007 based on a 2001 study of Tank 241-AY-101, the only tank at the time that used multiple risers (four actually) in an inspection. Riser variability was indicated, so rather than incorporating an extra uncertainty buffer when inspecting only a single riser, it was decided to inspect two risers instead. Now however it is shown in this report that such riser differences are not indicated in the more extensive set of tanks that now have inspections completed using multiple risers.

Since riser variability does not appear to contribute to variability in wall thickness loss in the 2007 inspections, there appears to be little reason to continue the multiple riser requirement in tank inspections. More paths down a single riser would likely offer better information (i.e., 4 scans from one riser, versus 2 scans from two different risers). And if the systematic differences between paths that influenced the older inspections, as discussed above, continue to occur, the needed re-inspections will be more readily identified when 3 or 4 paths have been inspected down the single riser.

For extreme value statistical estimation a single riser should be sufficient, but adequate numbers of measurements are still needed, which is another reason for 3 or 4 paths down from a single riser. 


\subsection{References}

Duncan, JB, and RB Wyrwas. 2007. Electrochemical Corrosion Report for Tanks 241-AW-103, 241AN-106, 241-AN-107, 241-AY-101, and 241-AY-102, RPP-RPT-34697, Rev 0, August 2007, CH2M HILL Hanford Group, Inc., Richland, Washington.

Jensen, CE, 2005, Engineering Task Plan for the Ultrasonic Inspection of Hanford Double-Shell Tanks FY2006 and FY2007, RPP-PLAN-27202, Rev 0, October 2005, CH2M HILL Hanford Group, Inc., Richland, Washington.

Weier DR, KK Andersen, and HS Berman. 2005. Riser Difference Uncertainty Methodology Based on Tank AY-101 Wall Thickness Measurements with Application to Tank AN-107, PNNL-15182, Pacific Northwest National Laboratory, Richland, Washington. 


\section{Appendix A}

UT Operator Minimum, Average, and Maximum Analysis 


\section{Method for Choosing the Minimum Tank Wall Thickness}

The analysis for minimum values begins with the thickness display level well above the minimum thickness anticipated for the plate. As shown in Figure A.1, the display level is set at 0.54-in. and the section of plate examined (the $4^{\text {th }}$ foot of Plate \#3 on Tank 241-AW-103) shows a relative uniform display. The display level is gradually reduced to find the minimum value in that foot section of Plate \#3. In the figure there are three views, the top, the side, and the end. The operator is able to display the remaining wall thickness by lowering the threshold bar (shown in blue on side view). Please note that the annulus side of the measured wall (primary tank outside diameter (OD)) begins at 0-in. in the side view so to lower the threshold bar means moving the blue bar upward (grey area is the actual wall thickness). Figure A.2 shows this display reduction in 0.1-in. increments until the final pixel amplitude is gone. Each pixel in the display has a dimension of 0.035-in. x 0.035-in. As shown in the last image in Figure A.2, the display no longer shows any pixel amplitude indicating a plate thickness less than 0.479-in. which is recorded as the minimum thickness in this plate section.

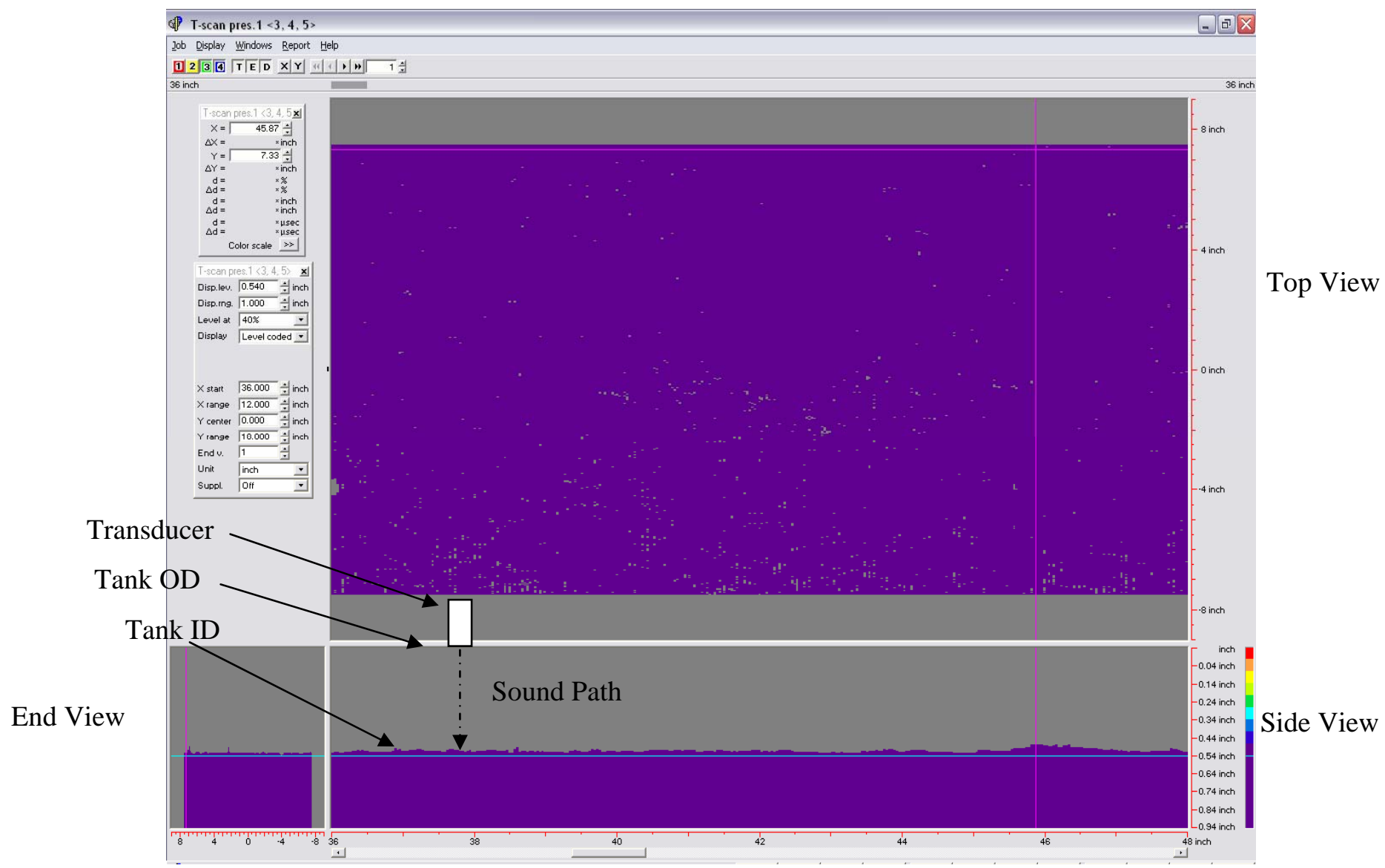

Figure A.1 Amplitude Well Above Minimum Anticipated Thickness 

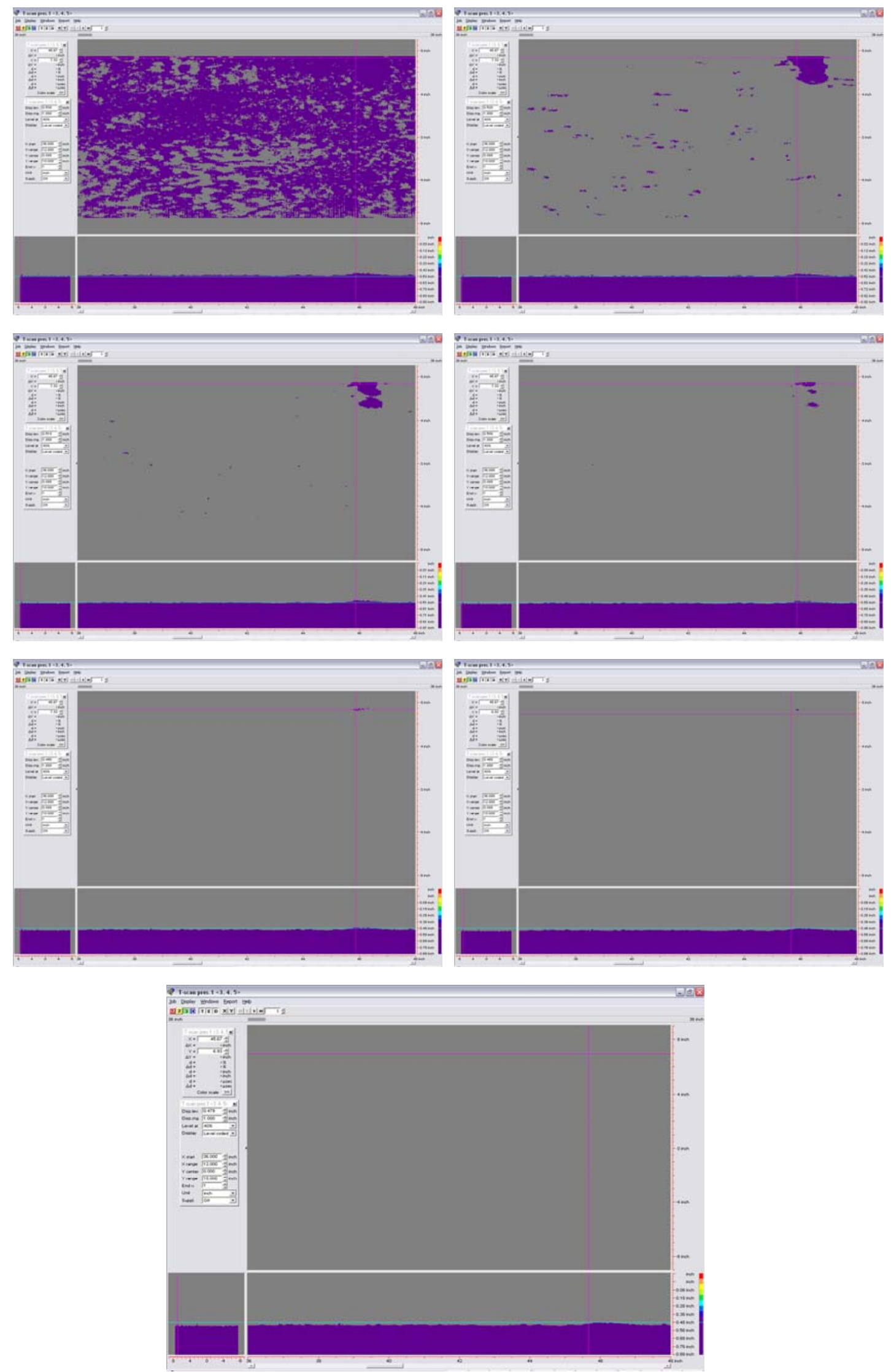

Figure A.2 Minimum Value Analysis

A-3 


\section{Method for Choosing the "Average” Tank Wall Thickness}

In the analysis of the "average" value a similar approach is taken. The analyst evaluates the screen displays and makes a visual assessment as to what he feels is 50-50 condition between colored and noncolored pixels. It is evident when performing the analysis that some areas (one foot sections that are being analyzed) are more easily assigned an "average" thickness based on this procedure. Initially evaluating the placement of the threshold bar in the side view gives a good starting point for the analysis. The rest of the analysis is a judgment of the best location that represents average. In actuality this measurement is a median measurement. Figure A.3 provides a display of pixel amplitudes that are either too sparse or too concentrated and would not be consider at the 50-50 point.
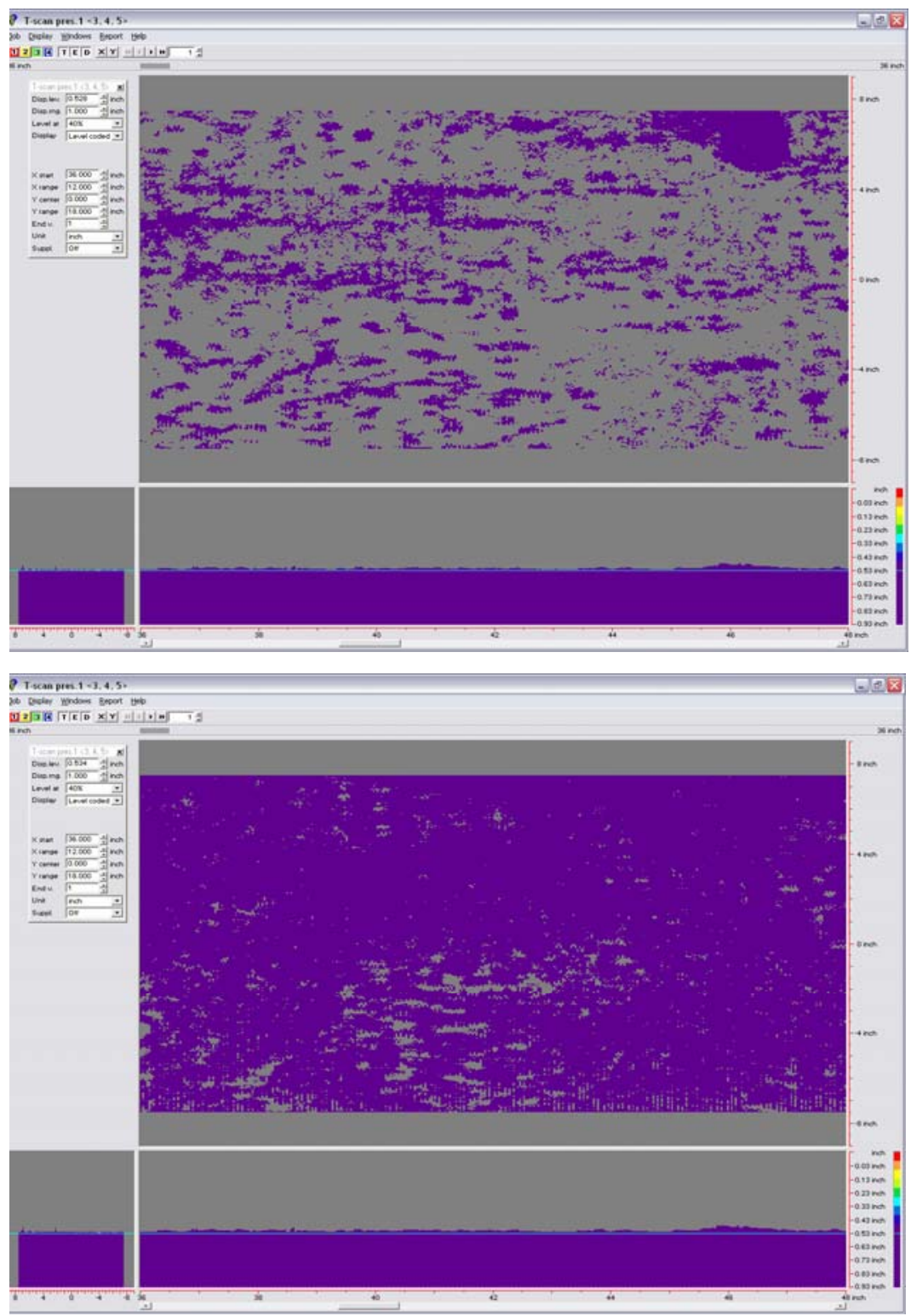

Figure A.3 Either Too Sparse or Too Concentrated 
Figure A.4 shows a reasonable distribution of grey and purple pixels indicating the location the operator chooses to consider the average value for reporting. In this case he chooses to identify the average value as 0.530 -in.

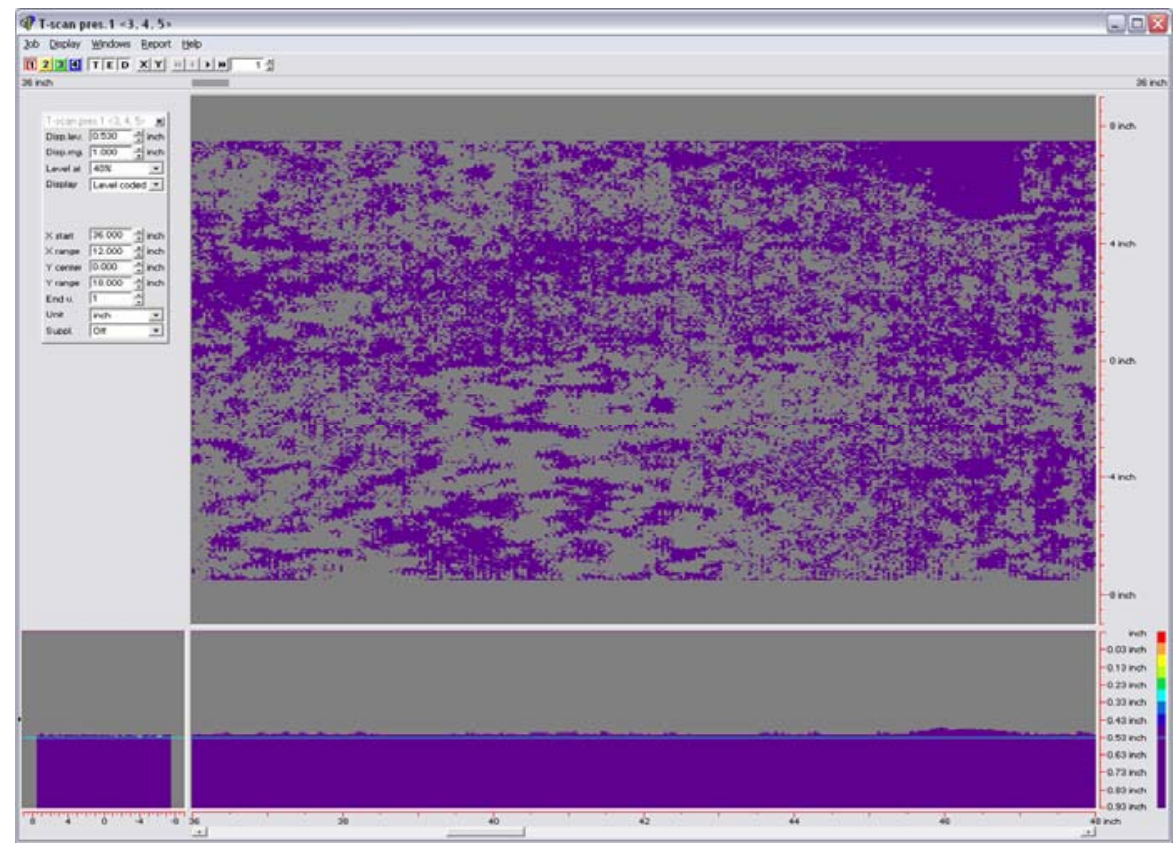

Figure A.4 Operator Chooses the “Average” Value

\section{Method for Choosing the "Maximum” Tank Wall Thickness}

Choosing the maximum wall thickness is done very similarly to doing the minimum thickness. However, random noise in the UT image does not allow the operator to simply move the threshold until the image is completely filled with purple pixels. Again, this is a judgment as to what the operator consider as a full screen of pixels. Figure A.5 provides the value chosen by the operator for the same $4^{\text {th }}$ foot as noted in the above images. The value chosen was 0.540 -in. The image still indicates some very small areas of grey pixels which are not considered relevant by the operator. Evaluating one of these areas with the software and running the threshold up to 0.60 -in., an unrealistic value (see Figure A.6), demonstrates that the values are random noise and should not be considered as maximum values in the analysis. 


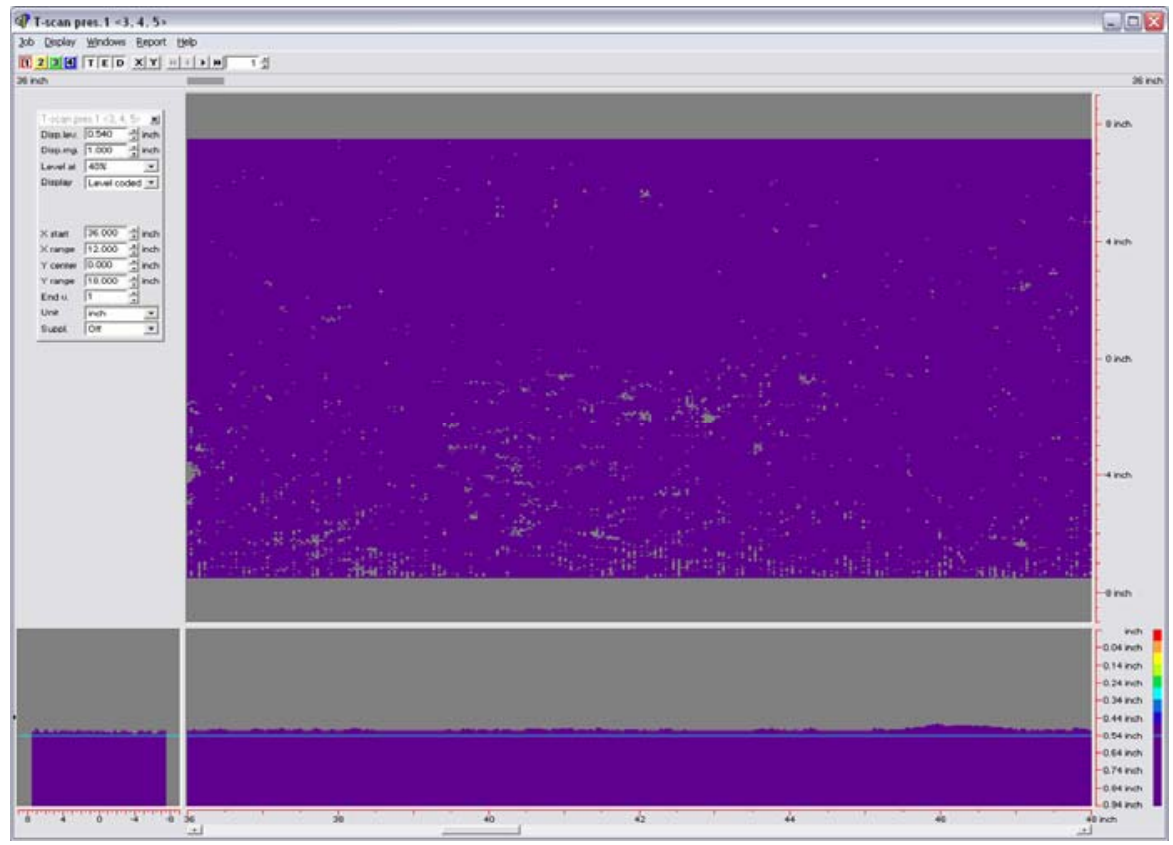

Figure A.5 Value Chosen by UT Operator as the Maximum Value

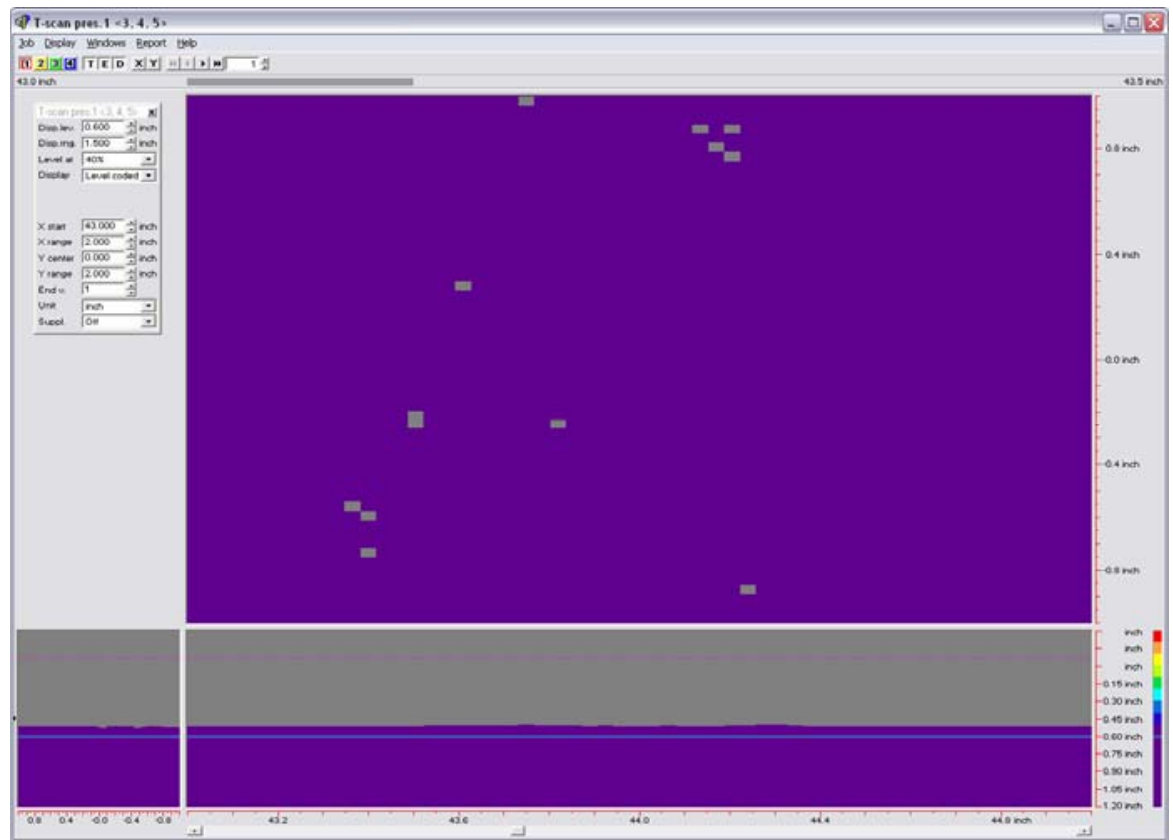

Figure A.6 Extreme Large Value to Demonstrate Random Noise 


\section{Distribution}

No. of

Copies

1 Hanford Site

H. S. Berman (1) R3-26

5 Pacific Northwest National Laboratory

S. L. Crawford (1) K5-26

A. F. Pardini (1) K5-26

G. J. Posakony (1) K5-26

M. L. Watkins (1) K5-26

D. R. Weier (1) K6-08

Distr-1 